\title{
Experimental and numerical investigation of geometric effect on cavitation flow through orifice
}

\author{
Mohammad Reza Davoudi and Miralam Mahdi* \\ Department of Mechanical Engineering, Shahid Rajaee Teacher Training University, Tehran, Iran
}

Received: 29 October 2019 / Accepted: 20 February 2021

\begin{abstract}
Due to the set of factors and conditions, the stream pressure through the orifice decreases, which can lead to the occurrence of the cavitation phenomenon. The most important factor in this regard is the geometry of orifice. In the first part of this study, the flow through two types of single-hole orifice and a multi-hole orifice were experimentally studied. The results showed that the single hole orifice with a two-sided sloped edge caused less pressure drop, which in order to control the cavitation phenomenon is more efficient compared to the single-hole and multi-hole orifices with one-sided sloped edges and the same equal diameter ratio. Additionally, all experiments were simulated in the second part of this research using finite volume methods. Considering the complexity of the problem, several numerical solutions were investigated to approach the experimental results. Finally, it was determined that the type of gridding, turbulence method, and cavitation model have a great influence on the accuracy of the obtained numerical results.
\end{abstract}

Keywords: Cavitation / multi-hole / orifice / pressure loss / sharp-edge

\section{Introduction}

Orifice plates as one of the main and important factors in the matter of energy dissipation and pressure reduction have been exploited in various industrial applications. Briefly, an orifice is a plate with a single or multiple holes. Flow characteristics of an orifice majorly depend on orifice size and its geometric features. In terms of thickness, orifices are generally divided into two classes by the criterion $\mathrm{t} / \mathrm{d}<0.5$ for thin and $\mathrm{t} / \mathrm{d}>0.5$ for thick orifices, in which $t$ represents the thickness of an orifice plate and $d$ indicates the hole diameter. The major application of orifices is the production of a constant pressure drop, which causes cavitation if the reduced pressure reaches the vapor pressure at the operating temperature. Cavitation, as an unwanted phenomenon, is one of the significant issues of concern in the industry due to its destructive features such as corrosion, vibration, noise, pressure fluctuations and efficiency reduction [1-4].

Sharp edge orifice plates are highly desirable because of their simplicity, ease of construction and reasonable price [5-8]. As an instance, in the Xianglodi hydropower project in China, three orifice plates in the downstream tunnel obtained an energy dissipation ratio of $44 \%$ in order to gain a complete control of flow velocity through a gate less than

\footnotetext{
* e-mail: M.mahdi@sru.ac.ir
}

$35 \mathrm{~m} / \mathrm{s}$ at the mechanical head of $135 \mathrm{~m}$ [9-12]. Orifice plates are widely used as refrigeration valves in refrigerating equipment and heat pumps. They are also used in hydrodynamic cavitation reactors, leading to the creation of high-pressure super cavitation, which can be applied to disinfect drinking water and sewage [13].

The presence of insoluble gases and solid particles suspended in water leads to formation of cavitation nuclei. Experiments show that there are always primary microns of nuclei in the water, which are usually spherical due to surface tension. During cavitation, these nuclei are directed to a low pressure zone (lower than saturated vapor pressure) and grow substantially in size so that they are visible with the naked eye. As bubbles enter the high pressure zone, they tend to collapse and release pressure waves in the liquid. During cavitation, interactions of bubbles with bubbles and fluid with bubbles are a highly important physical phenomenon that affects fluid flow behavior. Cavitation flows are generally divided into four categories, including Type I, Type II, Type III and Type IV according to the standard for control valve cavitation provided by international society of automation (ISARP75.23-1995). Type I is a cavitation free flow. Type II is an incipient cavitation, in which only small bubbles are observed in the flow path, which can be determined using sound measuring devices. Type III is a constant cavitation stream that has large and constant cavitation volume. Finally, the flow in Type IV reaches the most vibration 
state, which is the main characteristic of this stream [14-16].

In process with such a pressure drop, the cavitation phenomenon can cause various damage and corrosion to hydraulic devices such as water and oil streams, networks and pumping units. Cavitation is caused by a combination of geometric and hydrodynamic parameters. Main variables that affect the cavitation process are: 1 . the geometrical configuration of the device; 2 . absolute pressure in the cavitation region; 3 . critical pressure, which is generally assumed to be the liquid vapor pressure $\left(\mathrm{P}_{v}\right)$; and 4 . the pressure drop, which is generally considered as the pressure loss coefficient $(\xi)$. In order to quantify the intensity of cavitation, a non-dimensional parameter is defined, which is usually expressed as a ratio of the force preventing cavitation to the force causing it. In this paper, the cavitation number $(\sigma)$ is defined as

$$
\sigma=\frac{P_{1}-P_{v}}{\Delta P_{\text {net }}}
$$

where $\mathrm{P}_{1}$ is the upstream pressure and $\Delta \mathrm{P}_{\text {net }}$ is the pressure drop across the orifice [17]. The cavitation number $\sigma$ is defined based on the amount of cavitation in various states. Incipient cavitation, which is represented as $\sigma_{i}$ and shows the onset of Type II cavitation flowregime, the constant cavitation number $\sigma_{\mathrm{c}}$, which is indicated the cavitation number of flow between the second and third cavitation flow regimes and $\sigma_{\mathrm{mv}}$ as the cavitation number of maximum vibration which represents the cavitation number of a cavitation flow between the III and IV Type cavitation regimes. Based on the standard ISA-RP75.231995 and IEC 60534-8-2 (intelligent electronic devices) $[18,19]$, the initial cavitation value is determined experimentally by a semi-logarithmic plot of the sound pressure level (SPL) against the cavitation number $\sigma$. With a sudden increase in the trend of sound level, the change in the type of cavitation is determined [16]. Furthermore, the discharge coefficient $C_{d}$ and pressure loss coefficient $\xi$ in this paper are expressed as:

$$
\begin{gathered}
C_{d}=\frac{V}{\sqrt{\frac{2 \Delta P_{\mathrm{net}}}{\rho}+V^{2}}} \\
\xi=\frac{P_{1}-P_{2}}{\frac{1}{2} \rho v^{2}}
\end{gathered}
$$

where $\mathrm{V}$ is the average velocity of the flow through the orifice, $\Delta \mathrm{P}_{\text {net }}$ is the pressure difference across the orifice, $\rho$ is density and $\mathrm{P}_{1}$ and $\mathrm{P}_{2}$ are respectively the static pressures immediately before and after the orifice plate $[19,20]$.

He and Zhao [21] numerically analyzed flow through multistage orifices and found that in the Reynolds number (Re) less than $10^{5}$, the energy loss coefficient $\mathrm{K}$ decreased strongly with increasing the Re, and in flows with the Re larger than $10^{5}$, the value of $\mathrm{K}$ was almost constant. Moreover, with the increment of the contraction ratio $(\beta)$, which is defined as the orifice diameter to pipe diameter ratio, the $\mathrm{K}$ value and returned flow length varied with the same pattern and opposite to the contraction ratio trend. In multistage orifices, $\mathrm{K}_{2}$, which is the energy loss coefficient in the second orifice, is always smaller than the coefficient of the first orifice. By considering the ratio of the length between the orifices to the pipe diameter $(\mathrm{L} / \mathrm{D})$, this value must be greater than 5.5D. Thus, the second orifice could play the dissipation role completely. The same results were obtained experimentally and numerically by Xeng and Qi [22].

Testud [23] experimentally tested noise produced by cavitation in single-hole and multi-hole sharp-edge orifices with an equivalent diameter ratio in the developed cavitation and cloud-cavitation regimes according to the definition of Tulis. The equal diameter ratio (EDR) for multi-hole orifice was calculated according to:

$$
E D R=\sqrt{n} \times \frac{d_{0}}{D_{p}}
$$

where $\mathrm{d}_{o}$ is the diameter of the same holes, $\mathrm{D}_{P}$ is the diameter of the pipe, and $\mathrm{n}$ is the number of holes. They found that in the developed cavitation regime, sound generated in the multi-hole orifice was far greater than the equivalent value of the single-hole orifice. However, in the course of super cavitation, no difference was found between their results.

Fossa and Gugliemini [24] investigated pressure drop in horizontal streams through thin and thick orifices for single-phase and two-phase flows. According to the results obtained from their research in single-phase flows through thin orifices, an increase in thickness caused a relative decrease in the pressure drop coefficient. Additionally, the dependence of pressure drop on thickness in two-phase flows appeared less than the same value in single-phase flows.

Yan and Thorpe [25] experimentally analyzed various cavitation flow regimes with the effects of air injection in downstream flow through thin orifices. According to the research, incipient cavitation occurred by transition of the single-phase mode to the two-phase mode with bubbles formation. Moreover, they stated that incipient cavitation was highly dependent on the orifice diameter/pipe diameter ratio $(\beta)$ and on the pipe diameter itself $(D)$. They also showed the independence of the incipient cavitation number (for specific diameters) on the flow rate of the water. Xang and Cai [26] published an experiment, in which a test was conducted over the amount of pressure drops caused by different types of edge in flow through orifices to obtain the lowest content. As a result, the orifice plate which produced the least pressure drop had the lowest risk of cavitation occurrence. The high impact of the orifice geometry on the pressure loss was also indicated, in which the sloped edge orifice was considered as the optimal design resulting in the lowest pressure drop. $\mathrm{Wu}$ and Wan Zheng [27] numerically and experimentally investigated flow through orifice plates with various $\beta$ ratios and thicknesses. It was concluded that the pressure drop coefficient was only a function of the geometric parameters of the plate and diameter of the pipe and also was independent of the Re. This result is consistent with the results of Yan and Thorpe. 
Gan and Riffat numerically studied single-phase flow through a square edge orifice plate and a $2 \mathrm{~mm}$ thickness multi-hole orifice. They reported that the anticipated loss coefficient by CFD simulations shows less than $3 \%$ deviation from experimental results for the multi-hole orifice plate and more than $8 \%$ deviation for a single hole orifice plate. They observed decreation in the amount of flow and pressure in the use of a multi-hole orifice plate.

Takahashi and Matsuda [28] investigated shock pressure caused by the collapse of bubbles for three orifices of single-hole, multi-perforated, and cone type with the same EDR. It was concluded from their research that at low cavitation number, maximum shock pressure was observed near the pipe wall of the multi-perforated and cone type orifices and at the downstream edge of the single-hole orifice. They also mentioned that the maximum shock pressure was the lowest on the cone type orifice and the highest on the single-hole orifice. Ai [29] numerically analyzed energy dissipation through a thin orifice, and concluded that the energy loss coefficient and returned flow length were both functions of the contraction ratio.

Rudolf et al experimented five orifices with various hole numbers and orders in both single phase and multiphase flow. According to this research, although only one of these orifices fulfills Idelcik's definition of thick orifice plate, loss coefficient decreses even in a thin orifice [30]. Simpson and Ranade computationally studied various geometric parameters of the orifice, such as thickness, sharpness of the inlet edge and the slope of the edge, on the cavitation behavior. They presented the formulation and numerical solution of dynamic models of multiphase computational fluids (CFDs) and acknowledged that the input radius has a significant effect on cavitation activity. They provided a useful method for comparing and evaluating different cavitation device designs and operational parameters [31]. In addition, Mali et al. simulate flow through honeycomb shaped orifices and investigated the effect of various geometrical parameters such as flow area, the spacing between plates, number of plates, orientation between plates (inline or offset) on pressure drop, and cavitation characteristics. They reported that the flow pressure meet the lowest values at the orifice throat and near plate exit and an increase in the number of plates reduces the prospect of cavitation. They presented threshold flow velocity for different geometrical configurations, above which flow is subjected to cavitation [32].

According to articles and research on thin orifices, unlike thick orifices such as injector nozzles, it is clear that most research has been accomplished experimentally and the numerical studies on this issue are rare. Explicitly for two-phase flow, a few researchers have been studied cavitation in the incipient phase. Therfore, there are few references for the validation of the model in this case. In addition, experimental studies for thin orifices create pressure drop, for single-phase mode in which changes in discharge coefficient and pressure drop in terms of $\beta$ ratio have been investigated. Also, the hole geometry factors, which is one of the main feature influencing the performance of the orifice and cause changes in discharge coefficient, cavitation length, pressure drop and noise level, have not been fully understood.

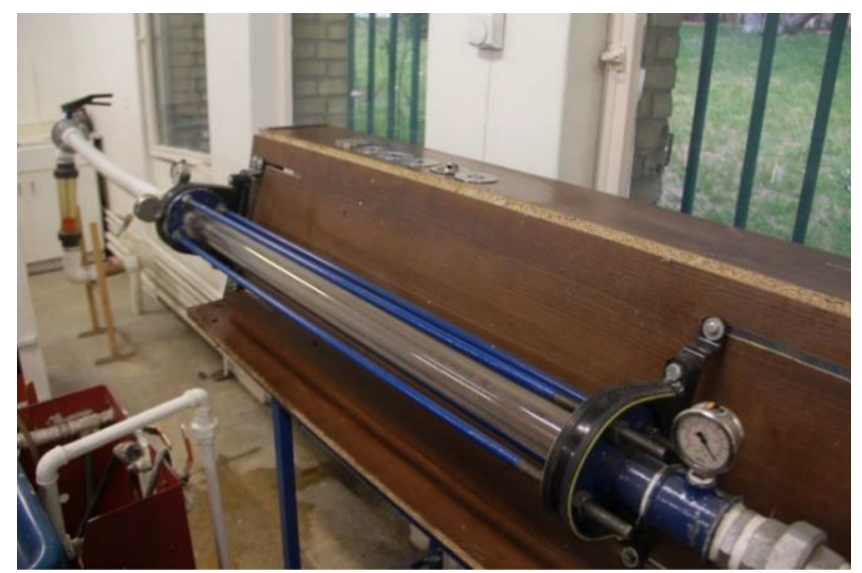

Fig. 1. The experimental setup of cavitation in the orifice.

In the present work, numerical and experimental comparisons of cavitation flow characteristics in thin orifices with two-sided sloped edge for various B ratio have been carried out in the first section and the same factors for a two-sided slope edge, one-sided slope edge as well as a multi-hole orifice with same EDR have been compared in the second section. Furthermore, the multiphase mixture model, related to an appropriate cavitation model, is utilized to simulate the flow-through thin orifices. The impact of various geometrical parameters such as flow area and the edge shape of the hole on pressure drop and cavitation specifications such as cavitation number and the noise level have been contemplated. In view of the outcomes obtained by the CFD studies in comparison with the acquired experimental results, cavitation performance for different configurations has been established.

\section{Experimental setup}

The test setup of this study, as shown in Figure 1, was designed according to standard 5167 by international organization for standardization (ISO 5167) [33] and was located at the Fluid Mechanics Laboratory Site of the Shahid Rajaee Teacher Training University. For the ease of replacement, the orifice plate was assembled within a flange. Moreover, in order to observe the cavitation phenomenon, a glass pipe was installed in the downstream of flow with an internal diameter of $\mathrm{D}=2^{\prime \prime}$ and a length of $23 \mathrm{D}$. A control valve was located at the $25 \mathrm{D}$ upstream of the orifice to adjust the flow rate. The valve was connected to the flange of the orifice with a polymeric pipe of $1.5^{\prime \prime}$ diameter and $1.5 \mathrm{~m}$ length, a $1.5^{\prime \prime} / 2^{\prime \prime}$ pipe connector of $75 \mathrm{~mm}$ length, and a branch pipe fitting of $60.8 \mathrm{~mm}$ diameter and $4 \mathrm{~cm}$ length to install the pressure gauge, and finally, a steel flange connection with $120 \mathrm{~mm}$ length and $2^{\prime \prime}$ diameter.

A pressure gauge was installed on the branch pipe fitting with an accuracy of $\pm 0.1 \mathrm{bar}$. Moreover, two vacuum gauges with the accuracy of \pm 0.02 bar and $\pm 20 \mathrm{~mm} \mathrm{Hg}$ were located respectively on the downstream orifice flange and the branch pipe fitting in $26 \mathrm{D}$ downstream from the orifice location. In order to measure the flow rate, a rotameter 


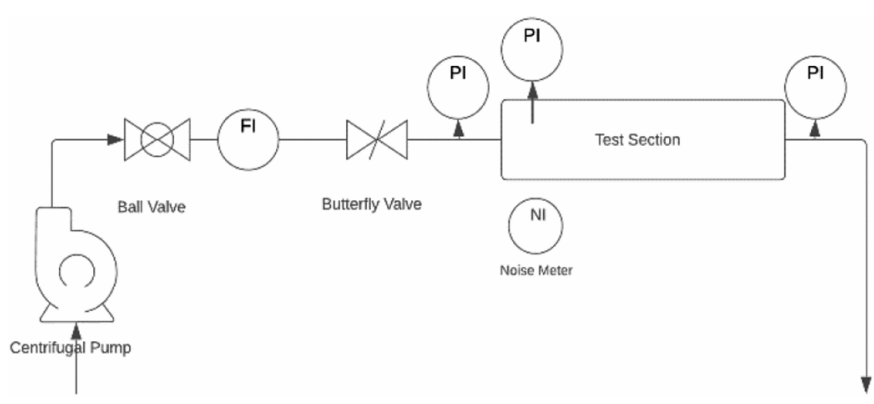

Fig. 2. The piping and instrumentation diagram of the experimental process.

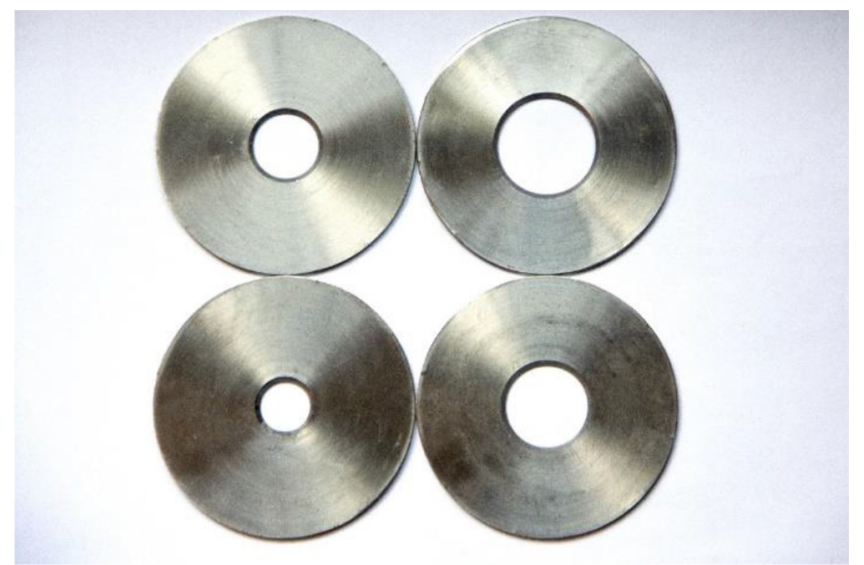

Fig. 3. Orifices with $0.3,0.4,0.5$ and 0.6 contraction ratio $(\beta)$.

in the range of $8-40 \mathrm{~m}^{2} / \mathrm{h}$ was used. The generated noises were measured using a portable sound level meter (RS232 ) during the experiments at the distance of $1 \mathrm{~cm}$ from the downstream flange and $0.5 \mathrm{~cm}$ from the glass pipe. Figure 2 shows the piping and instrumentation diagram (P\&ID) of the setup. The understudy orifices in this project included four single-hole orifices with a two-side sloped edge at the contraction ratio $(\beta)$ of $0.3,0.4,0.5$ and 0.6 , one single-hole orifice with a one-sided sloped edge and one multi-hole orifice with the same EDR of 0.4. Each of the six orifices mentioned above had a thickness and an outer diameter of 2 and $80 \mathrm{~mm}$, respectively, as described in Figure 3.

A multi-perforated orifice with four holes of $10 \mathrm{~mm}$ diameter and an equal diameter ratio of 0.4 was considered in order to be compared with single-hole orifices at a contraction ratio of 0.4 . The four single-hole orifices were constructed with a $45^{\circ}$ slope on both downstream and upstream edges. However, the other orifices with the same EDR (equal diameter ratio) of 0.4 were designed with only one edge to the downstream side to compare the shape effects of the edges. As shown in Figure 4, the downstream slopes were constructed with $1.5 \mathrm{~mm}$ thickness in plates with $2 \mathrm{~mm}$ thickness and remained untouched for one-sided sloped edge orifices. However, for two-sided sloped edge orifices, the rest of the edges were sloped to the upstream side.

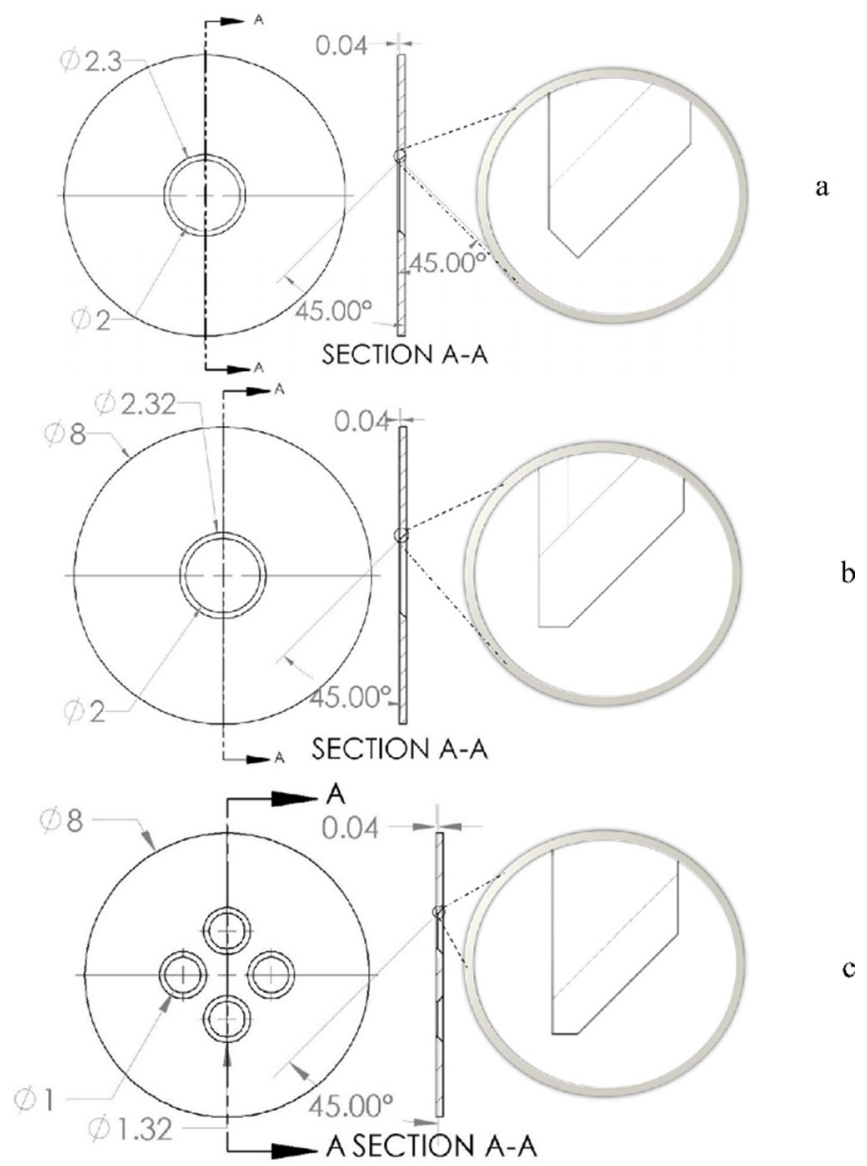

Fig. 4. The geometric shape of (a) a single-hole orifice with a two-sided sloped edge, (b) a single-hole orifice with a one-sided sloped edge and (c) a multi-hole orifice with a one-sided sloped edge.

\subsection{Section one}

The purpose of this section was to investigate the behavior of streams passing through the orifices with a two-sided sloped edge. As mentioned above, the under study orifices for this section consisted of four single-hole orifice plates at the contraction ratio of $0.3,0.4,0.5$ and 0.6 . They were separately located at the place embedded in the flange. Afterwards, by opening the inlet control valve, the water flow passed through the flowmeter and control valve to the orifice section. Eventually, the flow passed through the glass pipe and was damped out of the system. This process was performed for each orifice in various flowrates. Therefore, the flow rate indicated by the manometer was considered as the input of each test. While the output included the static pressure of upstream and downstream of orifice location, static pressure of discharge flow, produced sound level and length of cavitation when occurring. The manometer was incapable of measuring flow rates below $8 \mathrm{~m}^{3} / \mathrm{h}$. Furthermore, all the experiments were carried out in the cavitation zone prior to the chock cavitation regime and up to the available flow rate by the system pump. The results for orifices at diameter ratios of 0.3 and 0.4 are presented in Tables 1 and 2, respectively. 
Table 1. The experimental results for the orifice with the 0.3 contraction ratio.

\begin{tabular}{llllcc}
\hline $\mathrm{Q}\left(\mathrm{m}^{3} / \mathrm{h}\right)$ & $\mathrm{P}_{1}($ bar $)$ & $\mathrm{P}_{2}($ bar $)$ & $\mathrm{P}_{3}($ bar $)$ & $\mathrm{L}(\mathrm{cm})$ & ASL $(\mathrm{dB})$ \\
\hline 8 & 1.15 & 0.6596 & 0.9 & 5 & 78.35 \\
10 & 1.8 & 0.6296 & 0.9 & 8 & 87 \\
12 & 2.4 & 0.5396 & 0.9 & 12 & 94.2 \\
14 & 3.2 & 0.4096 & 0.9 & 16 & 98.85 \\
16 & 4.35 & 0.2896 & 0.9 & 20 & 102.4 \\
18 & 5.8 & 0.0496 & 0.9 & 27 & 104.7 \\
19 & 6.34 & 0.0496 & 0.9 & 36 & 103.2 \\
\hline
\end{tabular}

Table 2. The experimental results for the orifice with the 0.4 contraction ratio.

\begin{tabular}{llllcc}
\hline $\mathrm{Q}\left(\mathrm{m}^{3} / \mathrm{h}\right)$ & $\mathrm{P}_{1}($ bar $)$ & $\mathrm{P}_{2}($ bar $)$ & $\mathrm{P}_{3}($ bar $)$ & $\mathrm{L}(\mathrm{cm})$ & ASL $(\mathrm{dB})$ \\
\hline 8 & 0.4 & 0.8096 & 0.9096 & 0 & 74.55 \\
10 & 0.59 & 0.7596 & 0.9096 & 0 & 76.3 \\
12 & 0.68 & 0.7196 & 0.8966 & 0 & 77.2 \\
14 & 0.9 & 0.6496 & 0.8836 & 0 & 85.25 \\
16 & 1.28 & 0.5196 & 0.8706 & 0 & 93.1 \\
18 & 1.6 & 0.4496 & 0.8576 & 5 & 99.9 \\
20 & 2.1 & 0.3496 & 0.8576 & 8 & 101.7 \\
22 & 2.5 & 0.2696 & 0.8836 & 10 & 102.55 \\
24 & 3.1 & 0.1146 & 0.8836 & 17 & 104.1 \\
26 & 3.8 & 0.0496 & 0.8836 & 26 & 104.85 \\
28 & 4.6 & 0.0496 & 0.8836 & 95 & 101.7 \\
28.5 & 4.8 & 0.0496 & 0.8836 & 120 & 102.25 \\
\hline
\end{tabular}

As shown in the data obtained from the experimental tests, increase in the flow rate caused an increase in upstream pressure, average sound level, and cavitation length, but a decrease in downstream pressure. Cavitation occurrence was also more likely with the growth of differential pressure across the orifice. The pressure of $\mathrm{P}_{3}$ varied unnoticeably due to the direct connection of external flow to atmosphere and was about the pressure of atmosphere. In Figure 5, the average sound level (ASL) changes for the discussed orifices are plotted against the flow rates.

As shown in Figure 5, by increasing the flow rate and creating the cavitation phenomenon, the sounds produced by the bubble collapse were heightened so that they exceeded the permissible sound limit for the human hearing range and caused damage. A slight decrease was shown at the end of the trends of the orifices with $\beta=0.3$ and $\beta=0.4$, which was due to the increase in the length of the cavitation and consequently change in the location of the bubble collapse to a place far away from the sound level meter. Rising the upstream pressure by increase in the flow rate resulted in an extremely high pressure difference across the orifice plate and eventually caused the cavitation growth. Figure 6 illustrates the change in the cavitation number to the flow rate variation for the mentioned orifices. The cavitation number decreased with increasing pressure in all

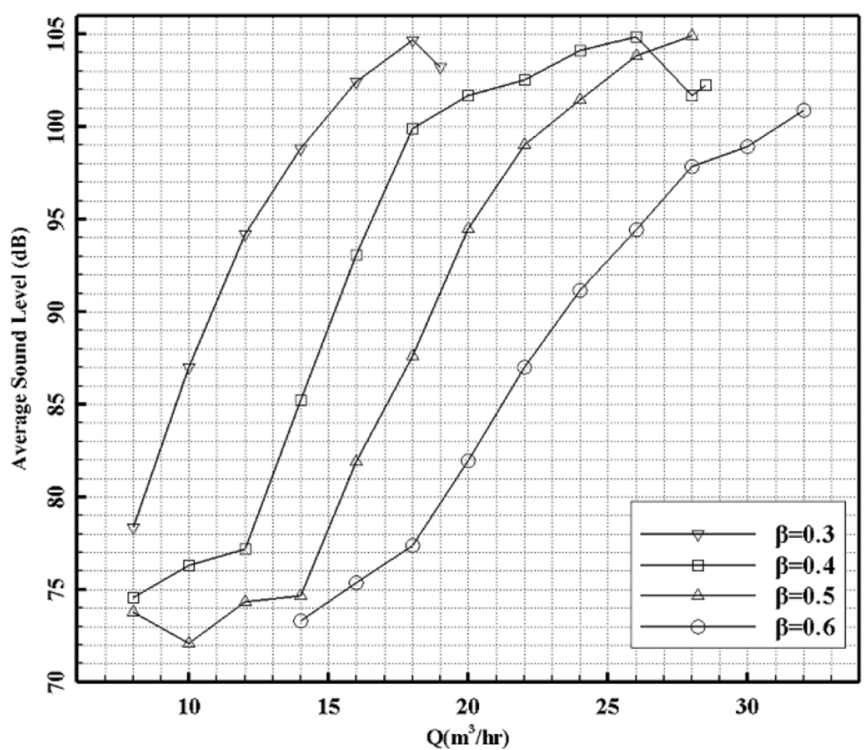

Fig. 5. Comparison of the ASL diagram with the flow rate change for different orifices.

the orifices. The pressure reduction continued until $\mathrm{P}_{2}$ met the vapor pressure of water at the operation temperature. In this article, a pressure of 4960 Pascal was considered as 


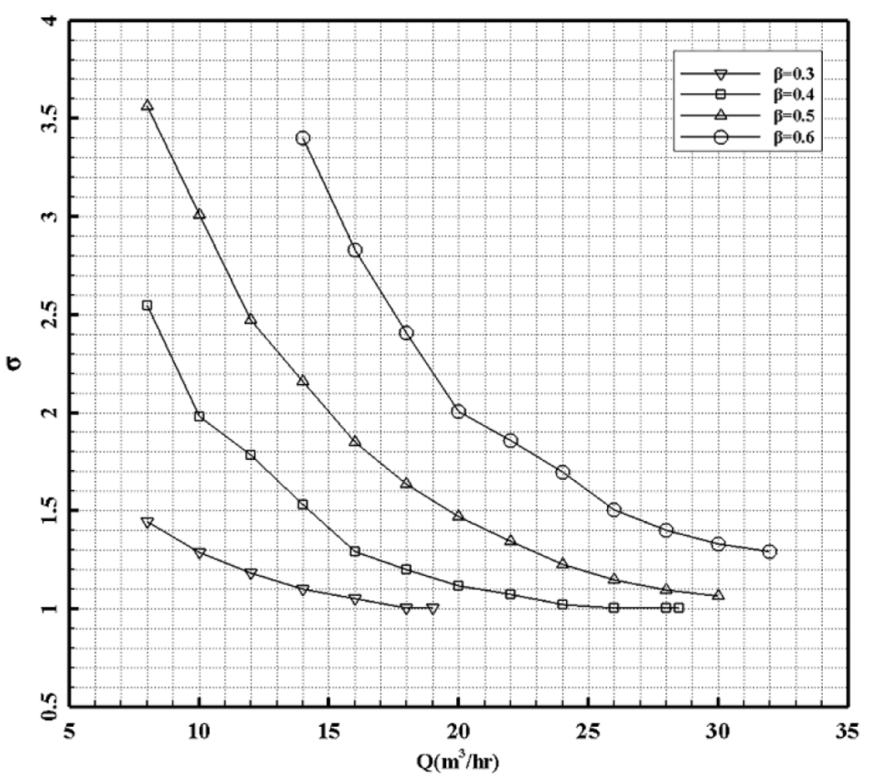

Fig. 6. Comparison of cavitation number variation for different orifices.

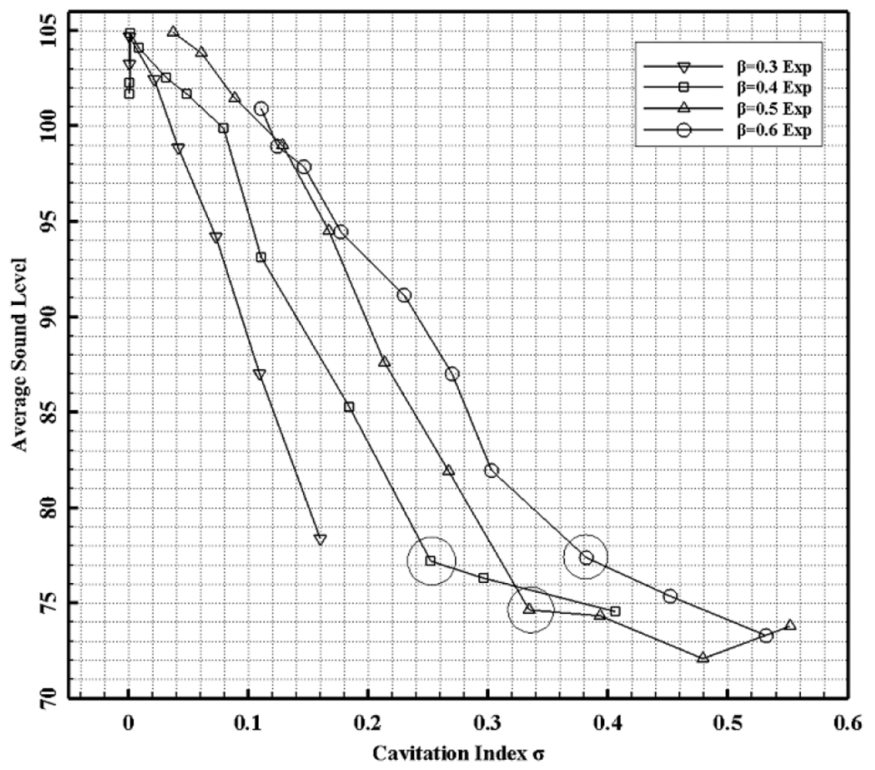

Fig. 7. The trend of ASL with the cavitation index change for different orifices. (The horizontal axis is in the logarithmic scale).

the vapor pressure in the laboratory condition. Therefore, the minimum cavitation number confined to 1 and further increase in pressure difference did not change the former factor. Furthermore, by growth in the amount of $\beta$, the cavitation number increased, meaning that cavitation occurred gradually. The graph of sound level changes to the cavitation number, as stated in the introduction section, indicated the amount of incipient cavitation. These trends are presented in Figure 7.

The decrease in the cavitation number $(\sigma)$ in each orifice was accompanied by an increase in the average sound level, in which a sudden change in the rate of this increase indicated a change in the cavitation flow type.

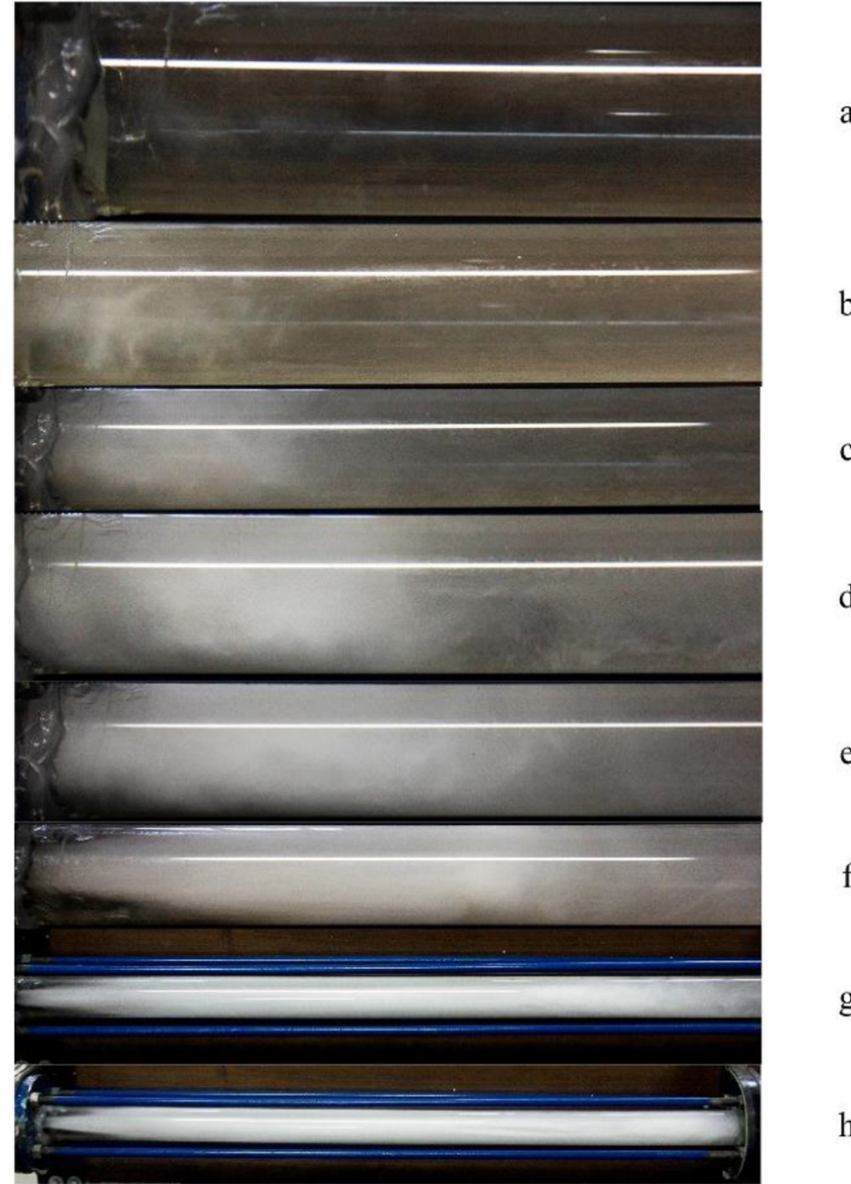

Fig. 8. The recorded photographs of the cavitation volume in the orifice with $\beta=0.4$ and in the flow rate of (a) 16 (b) 18 (c) 20 (d) 22 (e) 24 (f) 26 (g) 28 and (h) $28.5 \mathrm{~m}^{3} / \mathrm{h}$.

The change in the rates occurred at specified points, which, in fact, indicated the beginning of cavitation flow Type II. As shown in Figure 7, this point was not determined in the trend of $\beta=0.3$, and all the tests carried out on it in this study were in the incipient cavitation flowregime, with the exception of the last two tests that entered the constant cavitation range. The circled points of the other trends in the diagram indicated $\sigma_{i}$, which was represented as the incipient cavitation number. Inception cavitation occurred in the flow of $12 \mathrm{~m}^{2} / \mathrm{h}$ through the orifice with $\beta=0.4$, in the flow of $14 \mathrm{~m}^{2} / \mathrm{h}$ through the orifice with $\beta=0.5$, and in the flow of $18 \mathrm{~m}^{2} / \mathrm{h}$ through the orifice with $\beta=0.6$. In the initial streams of this phenomenon, cavitation was not particularly noticeable in the recorded images. In Figure 8, the captured photograph of the amount of cavitation during the tests is presented for each flow rate for the orifice with $\beta$ equal to 0.4 .

\subsection{Section two}

The purpose of this section was to compare the characteristics of the cavitation flow through the orifices with the same EDR equal to 0.4. These orifices consisted of a singlehole orifice plate with a one-sided sloped edge, a single-hole 
Table 3. The experimental results for the single-hole orifice with $\mathrm{EDR}=0.4$.

\begin{tabular}{|c|c|c|c|c|c|}
\hline $\mathrm{Q}\left(\mathrm{m}^{3} / \mathrm{h}\right)$ & $\mathrm{P}_{1}$ (bar) & $\mathrm{P}_{2}$ (bar) & $\mathrm{P}_{3}$ (bar) & $\mathrm{L}$ & $\mathrm{ASL}(\mathrm{dB})$ \\
\hline 8 & 1.4296 & 0.8696 & 0.9096 & & \\
\hline 10 & 1.6496 & 0.7896 & 0.89627 & & \\
\hline 12 & 1.8596 & 0.7316 & 0.89627 & & 78.3 \\
\hline 14 & 2.1096 & 0.6496 & 0.89627 & & 88.95 \\
\hline 16 & 2.4896 & 0.5296 & 0.89627 & 7 & 95.15 \\
\hline 18 & 2.9396 & 0.4296 & 0.89627 & 9 & 98.15 \\
\hline 20 & 3.5096 & 0.3196 & 0.89627 & 11 & 101.05 \\
\hline 22 & 4.0596 & 0.2096 & 0.89627 & 17 & 102.1 \\
\hline 24 & 4.7796 & 0.0696 & 0.88294 & 26 & 100.85 \\
\hline 25 & 5.1096 & 0.0696 & 0.88294 & 32 & 102.7 \\
\hline 26 & 5.4596 & 0.0596 & 0.88294 & 37 & 102.5 \\
\hline
\end{tabular}

Table 4. The experimental results for the multi-hole orifice with $\mathrm{EDR}=0.4$.

\begin{tabular}{llllll}
\hline $\mathrm{Q}\left(\mathrm{m}^{3} / \mathrm{h}\right)$ & $\mathrm{P}_{1}($ bar $)$ & $\mathrm{P}_{2}($ bar $)$ & $\mathrm{P}_{3}($ bar $)$ & $\mathrm{L}(\mathrm{cm})$ & ASL $(\mathrm{dB})$ \\
\hline 8 & 1.4596 & 0.8546 & 0.9096 & & 76.3 \\
10 & 1.6596 & 0.7896 & 0.8963 & & 82.75 \\
12 & 1.8696 & 0.7396 & 0.8963 & & 90.7 \\
14 & 2.1596 & 0.6396 & 0.8963 & 5 & 96.15 \\
16 & 2.5596 & 0.5096 & 0.8963 & 6 & 97.4 \\
18 & 3.0096 & 0.4396 & 0.8963 & 9 & 100.8 \\
20 & 3.5096 & 0.3096 & 0.8963 & 14 & 100.9 \\
22 & 4.1596 & 0.1796 & 0.8963 & 34 & 104.8 \\
24 & 4.8596 & 0.0796 & 0.8963 & 75 & 103.3 \\
25 & 5.2096 & 0.0896 & 0.8963 & 110 & 102.85 \\
26 & 5.8096 & 0.0896 & 0.8963 & & \\
\hline
\end{tabular}

orifice plate with a two-sided sloped edge and a multi-hole orifice plate, the characteristics of which are presented in Figure 4 . The results of flow through the orifice with a twosided sloped edge were presented in the first section. Similarly, flow through the orifice with a one-sided sloped edge and the multi-hole orifice was analyzed. In Tables 3 and 4 , the results of flow through the former orifices are displayed.

As shown in Tables 3 and 4, a growth in the flow rate increased upstream static pressure, probability of cavitation occurrence, length of cavitation, and noise level, but lowered downstream pressure. The variation of cavitation length, cavitation number, pressure loss coefficient, and generated sound level in these experiments was presented in order to better understand the effect of geometry. Figure 9 displays the graph of change in cavitation length due to various flow rates.

With gradual increase in the flow rate, cavitation was formed and intensified. As a result of this increase, cavitation length grew rapidly. As indicated in Figure 9, in low flow rates and in the early stages of cavitation, the multi-perforated orifice had a relatively smaller cavity length than the same single-hole orifices, especially the one

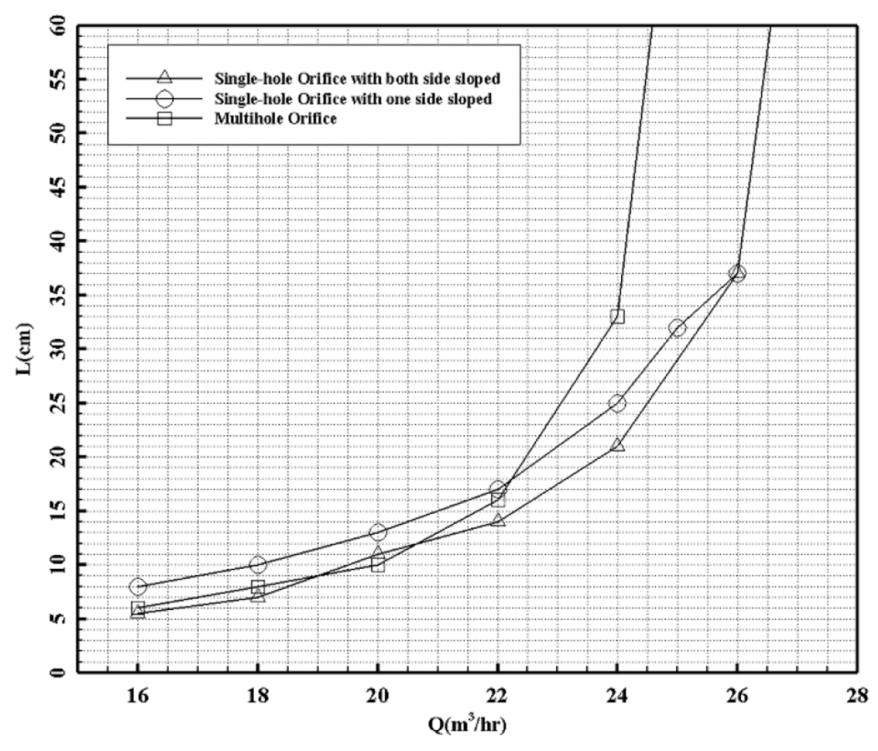

Fig. 9. Comparison of the trends of cavitation length against flow in a multi-hole orifice a single--hole orifice with a two-sided sloped edge and a single-hole orifice with a one-sided sloped edge. 


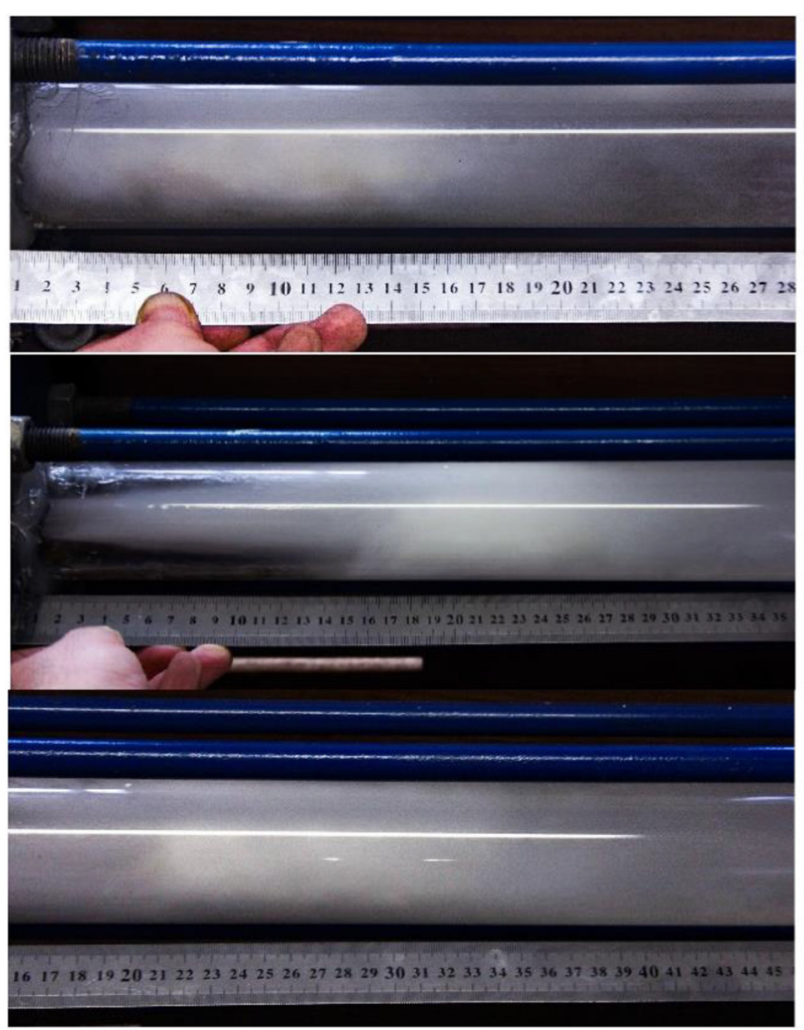

b

Fig. 10. Comparison of cavitation length in a same flow of $24 \mathrm{~m}^{3} / \mathrm{h}$ between (a) a single--hole orifice with a two-sided sloped edge, (b) a multi-hole orifice and (c) a single-hole orifice with a one-sided sloped edge.

with a one-sided sloped edge. By increasing the flow rate and cavitationlength, the trend of the multi-hole orifice grew more rapidly than the trend of the other two orifices. This indicated the inappropriateness of the multi-hole orifices in the case of super cavitationoccurrence so that in the flow rate of $26 \mathrm{~m}^{3} / \mathrm{h}$, the cavity length reached $110 \mathrm{~cm}$. The lines of the two single-hole orifice plates increased similarly with an approximately constant difference of $3 \mathrm{~cm}$ up to $26 \mathrm{~m}^{3} / \mathrm{h}$. As shown in Figure 10, in a discharge of $24 \mathrm{~m}^{3} / \mathrm{h}$, the formed cavity length in the multi-hole orifice exceeded the cavity length at the same flow rate in the single orifices. However, as Figure 11 indicates, it is noticeable that in the diagram of the cavity length against pressure difference, the multi-perforated orifice resulted in the minimum cavity length for the same pressure difference.

Figure 11 demonstrates that almost in every three orifices, measurable cavitation took place at a pressure difference of 2 bar and with increase in pressure difference, cavity length increased as well. It is shown that up to a pressure difference of 4 bar, flow through the multi-hole orifice obtained the lowest cavity length. However, with increasing pressure difference to more than 4 bar, the mentioned flow obtained the largest cavitation length and flow through the single-hole orifice with one-sided slopededge met the smallest cavity length. According to Figures 10 and 11, it is evident that the major difference between orifices with a two-sided sloped edge and other

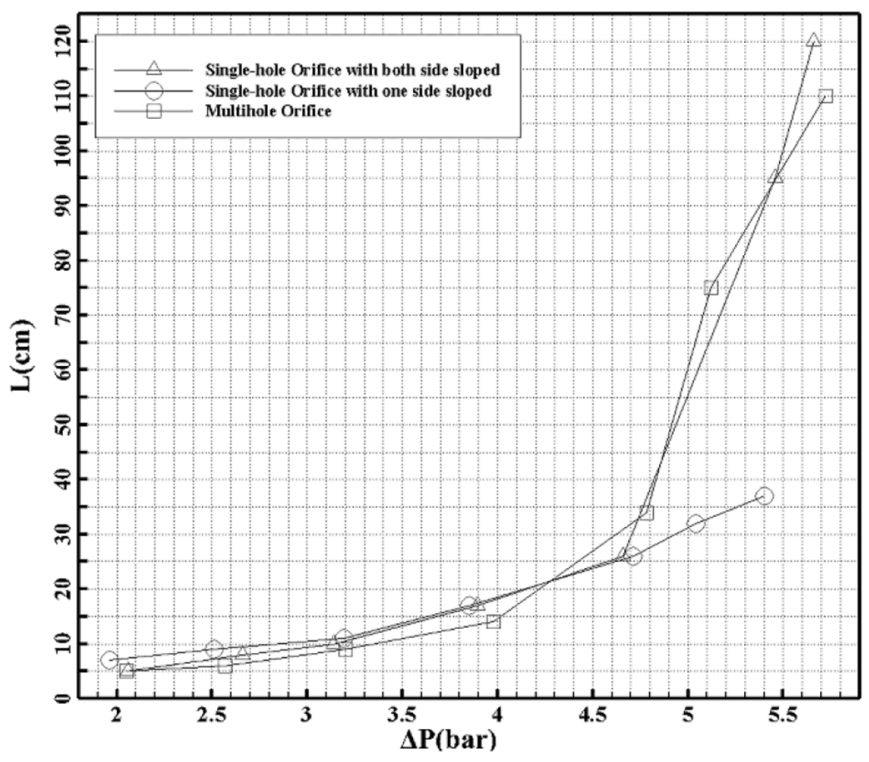

Fig. 11. Comparison of the trends of cavitation length against pressure difference across a multi-hole orifice, a single-hole orifice with a two-sided sloped edge and a single-hole orifice with a onesided sloped edge.

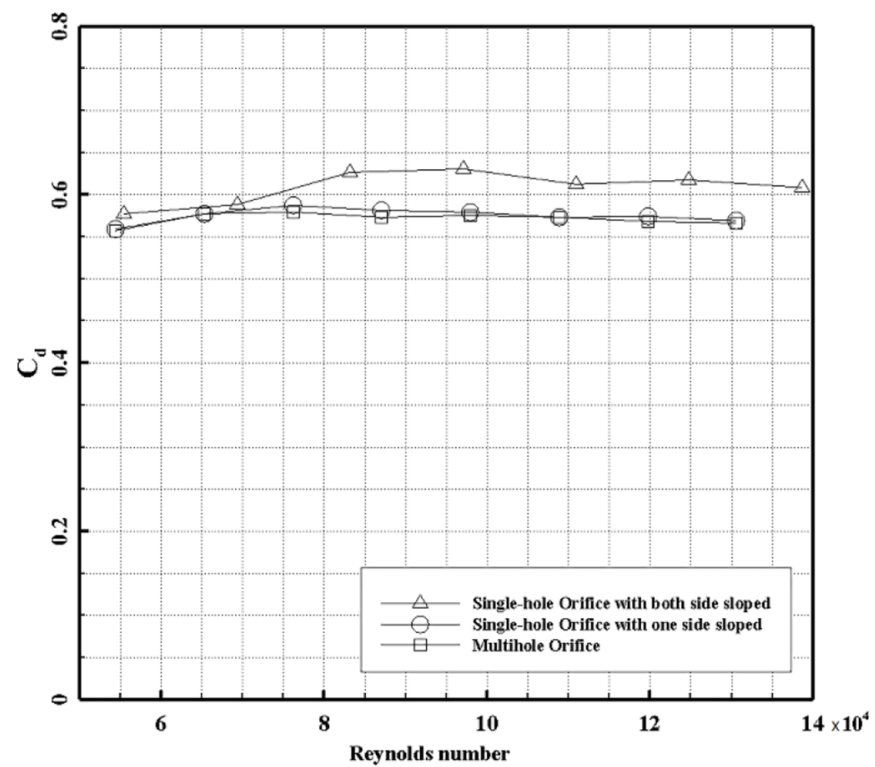

Fig. 12. Comparison of the trends of the discharge coefficient against the Rein a multi-hole orifice, a single--hole orifice with a two-sided sloped edge and a single-hole orifice with a one-sided sloped edge.

orifices is the amount of the discharge coefficient defined as the actual discharge ratio to the ideal flow rate in a constant Reynolds number.

This difference is clearly observed in Figure 12 . The value of the discharge coefficient in a given Re is greater in the previous orifice than in the other orifices. The comparison between the cavitation number and pressure loss coefficient of the mentioned orifices is shown in Figures 13 and 14, respectively. As the flow rate increased, 


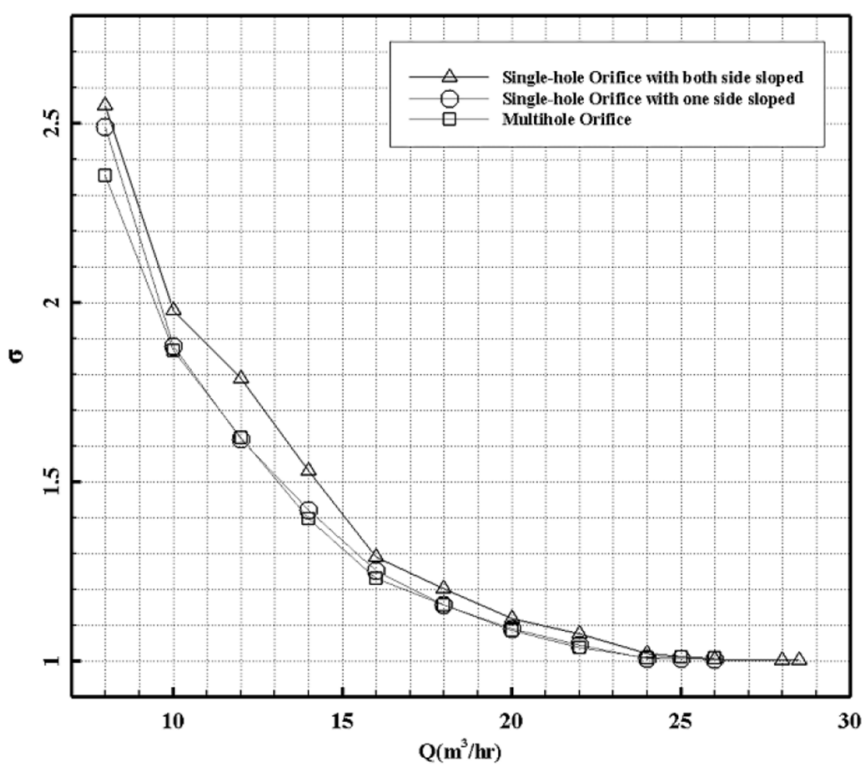

Fig. 13. Comparison of the cavitation number in a multi-hole orifice, a single--hole orifice with a two-sided sloped edge and a single-hole orifice with a one-sided sloped edge.

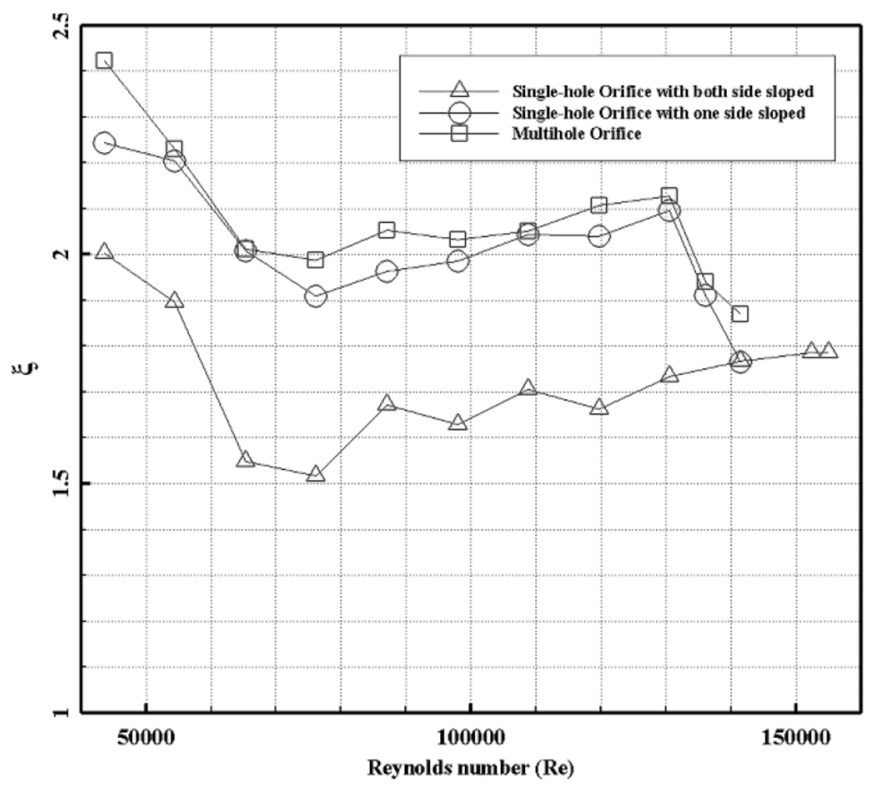

Fig. 14. Comparison of the pressure loss coefficient trend against the Rein a multi-hole orifice, a single--hole orifice with a two-sided sloped edge and a single-hole orifice with a one-sided sloped edge.

the probability of cavitation occurrence increased, which is clearly observed in Figure 13. For lower flow rates through these orifices, the cavitation numbers of different orifices had different gaps. Accordingly, the multi-perforated orifice, followed by the single-hole orifice with a one-sided sloped edge, had lower values of cavitation than the singlehole orifice with a two-sided sloped edge at the same discharge. This difference was reduced by increasing the flow rate to the minimum cavitation number of 1 .

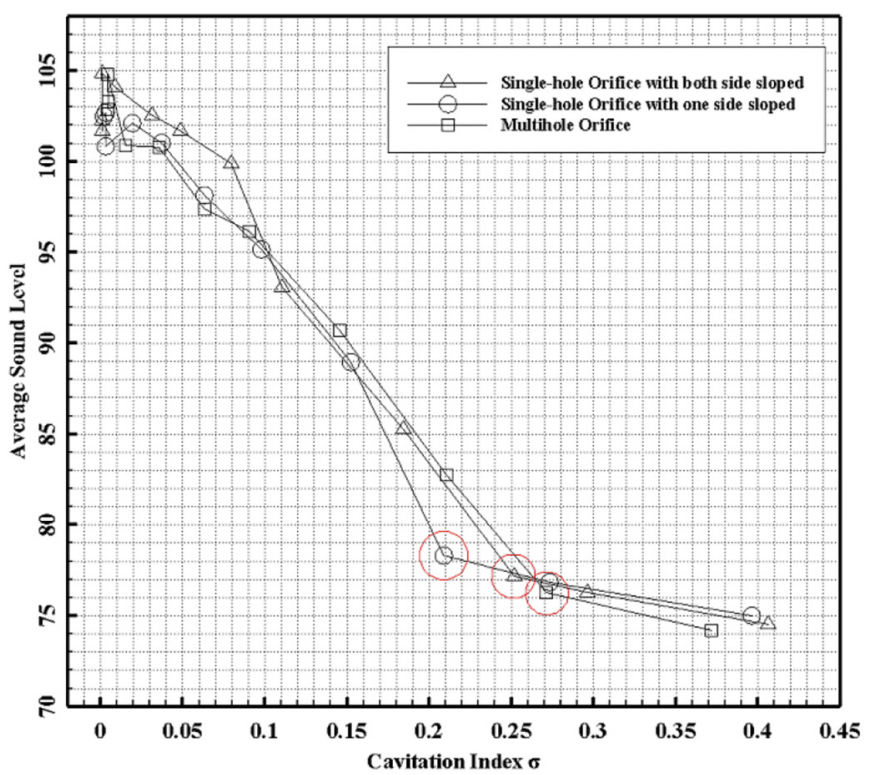

Fig. 15. The trend of ASL with the cavitation index change for different orifices. The horizontal axis is in the logarithmic scale.

As shown in Figure 14, it was deduced that the pressure loss coefficient, which actually indicated the pressure drop across the orifice with a two-sided sloped edge, had a relatively large difference with the same coefficients in a specific Refor both the single-hole orifice with a one-sided sloped edge and the multi-hole orifice. In other words, the flow through the single-hole two-sided sloped edge orifice had much lower pressure drop than the flow with the same Rethrough the other orifices. Furthermore, these lines had a downward trend up to the flow rate of $16 \mathrm{~m}^{3} / \mathrm{h}$, which was the point of incipient cavitation and after a cavitation formation, the trends were slightly elevated. According to the explanations given in the introduction section, the method for determining the initial cavitation value for these orifices was also analyzed, which is shown in Figure 15. In accordance to this semi logarithmic diagram, it was evident that the initial cavitation concentrated around 0.2 and 0.8 , meaning that cavitation occurred in the cavitation range of $1.86>\sigma>1.61$. The incipient cavitation value in this figure was specified for each orifice with red circle. Consequently, the incipient cavitation occurred in the flow rate of $10 \mathrm{~m}^{3} / \mathrm{h}$ for the multi-hole orifice and the flow rate of $12 \mathrm{~m}^{3} / \mathrm{h}$ for the other two orifices.

\section{Numerical simulations}

In accordance with the experimental equipment introduced in the former section, the flow path was simulated as in the experiments. Accordingly, the multi-hole orifice and singlehole orifice with a one-sided sloped edge were simulated in 3 dimensions (3-D) due to the specific geometry of the multihole orifice, while the rest of the single-hole orifices related to the section one of the experimental tests were simulated in 2 dimensions(2-D) axisymmetric. All the 3-D 
simulations in this paper were conducted using Ansys Fluent 16 and the 2-D models simulated by Ansys Fluent 19. First, a comparison was carried out between 2-D and 3 -D numerical analysis results for the single-hole orifice with a sloped edge and a negligible difference was observed. Since the numerical analysis of a 3-D model is much greater and more time consuming than that of a 2-D model, in this research, we used 2-D models to simulate the first-section experiments.

In order to discretize the flow domain, the commercial software Gambit 2.4.6 was used by quadrilateral axisymmetric pave elements for the 2-D models and tri-pave elemental type for the 3-D models. In order to obtain more precise results, the K- $\omega$ Menter's Shear Stress Transport (SST) turbulence model was used in this study.

SST k- $\omega$ model developed by Menter [34] is utilized to represent turbulence in the stream field. SST k- $\omega$ model is the composition of the $\mathrm{k}-\omega$ model for near-wall flows along with the $\mathrm{k}-\varepsilon$ model for the remaining flow domain. In order to calculate the effect of turbulent shear stress, the SST k- $\omega$ model contains improved turbulent viscosity formulation. Passing through an orifice can make the flow exposed to division, jet formation, or returning to the orifice walls, shear layers near orifice walls, major density ratio, and opposed pressure gradients. Consequently, the selected solver model needs to simulate disturbance in the stream field near the orifice walls as well as in the mass domain. The specifications of the SST k- $\omega$ model fulfill the features of the stream confronted in the present study. Bardina et al. [35] assessed the efficiency of different turbulent solvers in case of complex turbulent flows. In addition, they recommended utilizing the SST $\mathrm{k}-\omega$ model in case of complex flows involving division, jet formation, and opposed pressure gradients. Also, the SST k- $\omega$ model uses automatic wall function, which can alter between boundary layer calculation and log law estimation relying on mesh processing near the wall. Dastane et al. [36], Simpson and Ranade [37] have recommended solving the turbulence flow using the SST k-w model in case of complex cavitating flows.

Then, to meet the consideration of using this method, the mesh around the holes was fined in a way that the size of the boundary layer elements (0.005) around the holes in the 2-D models increased at a rate of 1.1 and reached a maximum of 0.6 in $+1 \mathrm{D}$ and $-1 \mathrm{D}$ from the orifice location. This condition extended to the maximum cell size of 0.8 to the $5 \mathrm{D}$ downstream of the orifice and, the rest parts of the grid were meshed by the assumption of the maximum element size of 1 . The final grids were constructed with about 440000 elements in 2-D models and about 1300000 in 3-D models. The geometrical scheme and grid structure of the single-hole orifice with a two-sided sloped edge at the contraction ratio of 0.4 are displayed in Figure 16 .

For the steady numerical simulation of flow along with the cavitation phenomenon, various models and methods were used. The obtained results for some of the methods differed significantly with the experimental data. In some cases, solutions were hardly converged or even diverged. The results showed that the use of Singhal et al.'s cavitation model in comparison to the other cavitation solving models obtained closer results to the experimental data.

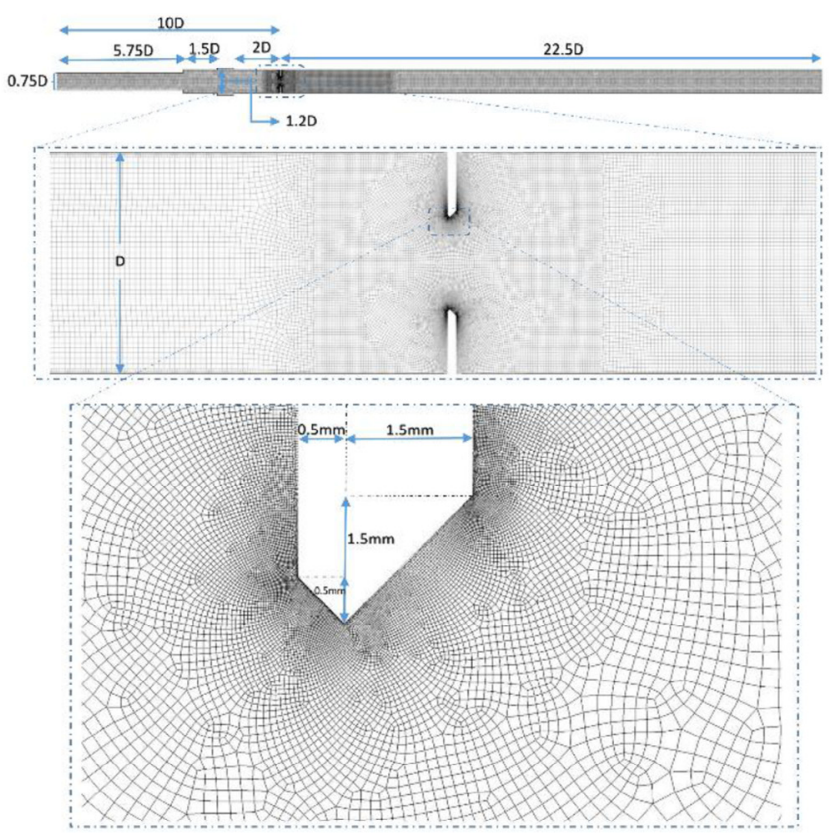

(a)

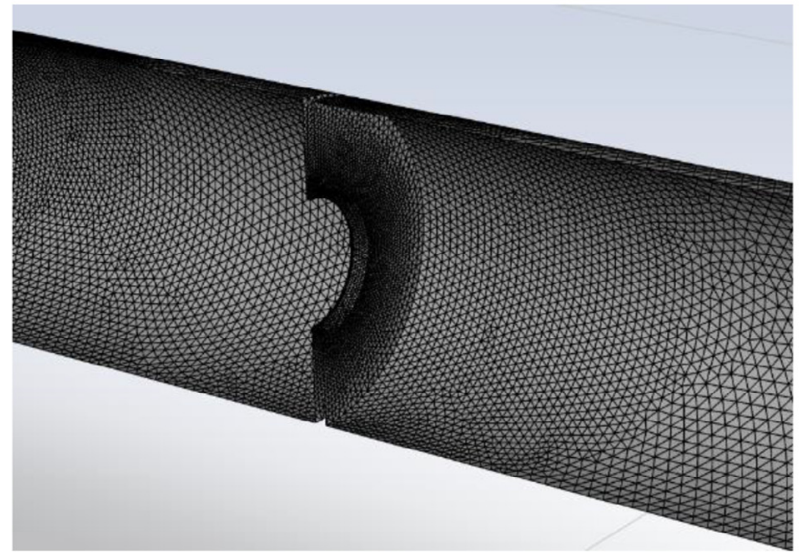

(b)

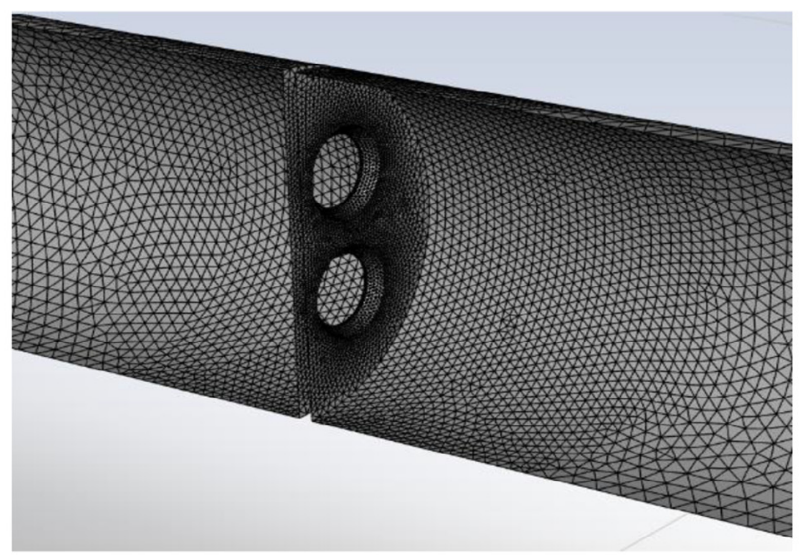

(c)

Fig. 16. (a) the 2-D geometrical scheme and mesh structure of the single-hole orifice with a two-sided sloped edge at $\beta=0.4$. (b) the 3-D mesh structure of the single-hole orifice with a onesided sloped edge at $\beta=0.4$. (c) the 3 - $\mathrm{D}$ mesh structure of the multi-hole orifice with two-sided sloped edge at $\mathrm{EDR}=0.4$. 
Several mass transfer solution methods have been offered to simulate the cavitation process, with the most regularly utilized methodologies based on decreased forms of the Rayleigh-Plesset equation. As an instance, the models of Schnerr and Sauer [38], Zwart et al. [39], and Singhal et al. [40], which have been developed to simulate the cavitation in the Ansys Fluent. All the multi-phase simulated flows in this paper are computed in use of latter cavitation model proposed by Singhal; validation of this method has been carried out in various study cases (Singhal et al. [40], Ebrahimi, et al. [41]); which has the advantage that the amount of bubble number per unit volume, n, need not be determined as input.

The effect of turbulence on cavitating flows has been shown in various experimental researches. Moreover, Singhal et al. proposed a numerical model, in the use of the probability density function (PDF) method for calculating the consequences of turbulent pressure fluctuations. The essentials for this method include: (a) assessment of the local amounts of the turbulent pressure fluctuations as:

$$
P_{\text {turb }}^{\prime}=0.39 \rho k
$$

and (b) calculation of time-averaged phase-change rates by the combination of instantaneous rates in association with assumed PDF for pressure alteration along with time. In the present study, this behavior has been simplified by merely altering the phase-change threshold pressure value as:

$$
P_{v}=\left(P_{\text {sat }}+\frac{P_{\text {turb }}^{\prime}}{2}\right)
$$

The running liquid in most engineering equipment includes a finite quantity of non-condensable gas (NCG) in a dissolved condition or owing to leakage or through aeration. Unexpectedly, a small amount (e.g., $10 \mathrm{ppm}$ ) of NCG can have considerable results on the dilatation of the gas at low pressure which can result in notable quantities of local gas volume fraction, and therefore have a significant impression on the distributions of density, velocity, and pressure. Another effect can be through increasing the phase-change threshold pressure which has been neglected because of the absence of general correction.

Among the turbulence models, as stated above, the K- $\omega$ SST turbulence model with fined elements around the holes provided more precise results. The right choice of relaxation factors resulted in better convergence with lower residuals. In this regard, in addition to considerations stated in the Fluent Software Guide, by decreasing the relaxation factors of pressure, momentum, evaporation mass and density, the solution converged quickly and appeared to obtain better convergence by increasing the density, evaporation mass and pressure coefficients after several iterations. Another influential factor in a better convergence is initialization. Accordingly, the solution was first solved without considering cavitation. Then, by turning single-phase flow to mixture flow and selecting cavitation as the transfer mechanism, the favorable initialization was obtained and the complex cavitation

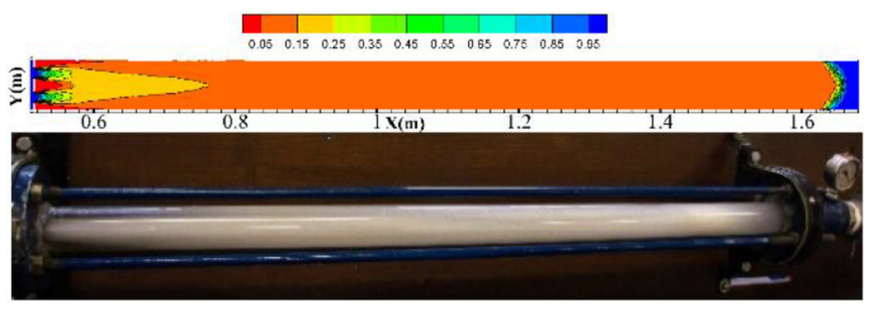

Fig. 17. Comparison of the numerical and experimental results of cavitation length in a same flow of $26 \mathrm{~m}^{3} / \mathrm{h}$ through a multi-hole orifice.

analyses with the best initial value were obtained. The cause of this initialization is the facilitated convergence of the single-phase flow in proportion to the multiphase flow. The boundary conditions were considered as the velocity inlet and pressure outlet. The operating temperature was $26{ }^{\circ} \mathrm{C}$, and the other specific values were considered as default.

Figure 17 illustrates the similarity of the achieved numerical and experimental result, which indicated a cavitation length of about $110 \mathrm{~cm}$, occurring in a flow rate of $26 \mathrm{~m}^{3} / \mathrm{h}$ through the multi-perforated orifice. In the numerical analysis of this research, inputs were considered in form of the velocity-inlet and outputs were regarded as the pressure outlet. The input velocity inlet of each test was calculated from the discharge and cross-sectional area of the pipe at the entrance. For the pressure outlet, the values were assumed as the obtained $\mathrm{P}_{3}$ results from the experimental data. The software calculated the pressure and velocity at each cell inside the flow model. The pressure-velocity coupled equations as well as the vapor equations were solved using the simple method and quick method, respectively, while the second order upwind method was employed to solve the remaining equations. Finally, the numerical models of this study were analyzed. The comparison of the cavitation numbers obtained from the experimental and numerical results is presented in Figures 18 and 19, respectively.

In Figure 18, changes in the number of cavitation against Reynolds number were compared between the results obtained from the experiment and simulated 2-D models for single-hole orifices with a two-sided sloped edge at the contraction ratio of $0.3,0.4,0.5$ and 0.6 . It was shown that by increasing the Reynolds, pressure difference and cavitation length increased, while the number of cavitation decreased. This trend became equal in both the numerical and empirical data. In lower flow rates, as mentioned, there was a greater difference between the results of the numerical analysis and the results obtained from the experimental tests. With the Reynolds increasing, this difference decreased significantly and the numerical result became more accurate.

The same diagram is shown in Figure 19 in order to compare the numerical and experimental results of orifices with the same EDR of 0.4 . Here, as previously mentioned, increase in the $R e$ was proportional to decreasing the number of cavitation. These trends were highly similar to each other, although the 2-D model cavitation number in 


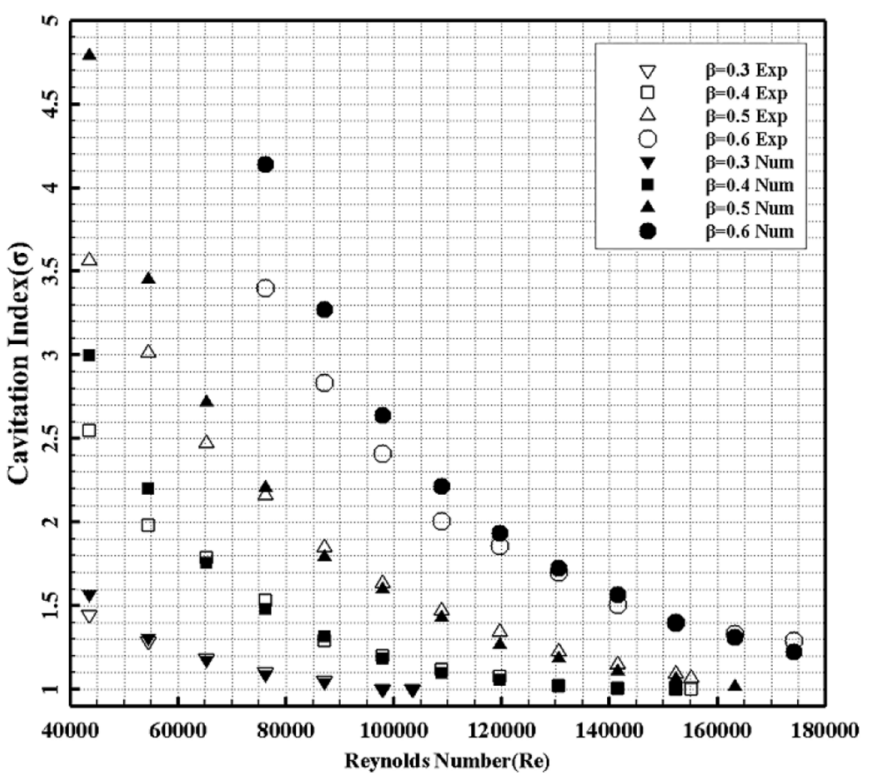

Fig. 18. Comparison of the resulted cavitation number variation for different orifices in the numerical and experimental experiments.

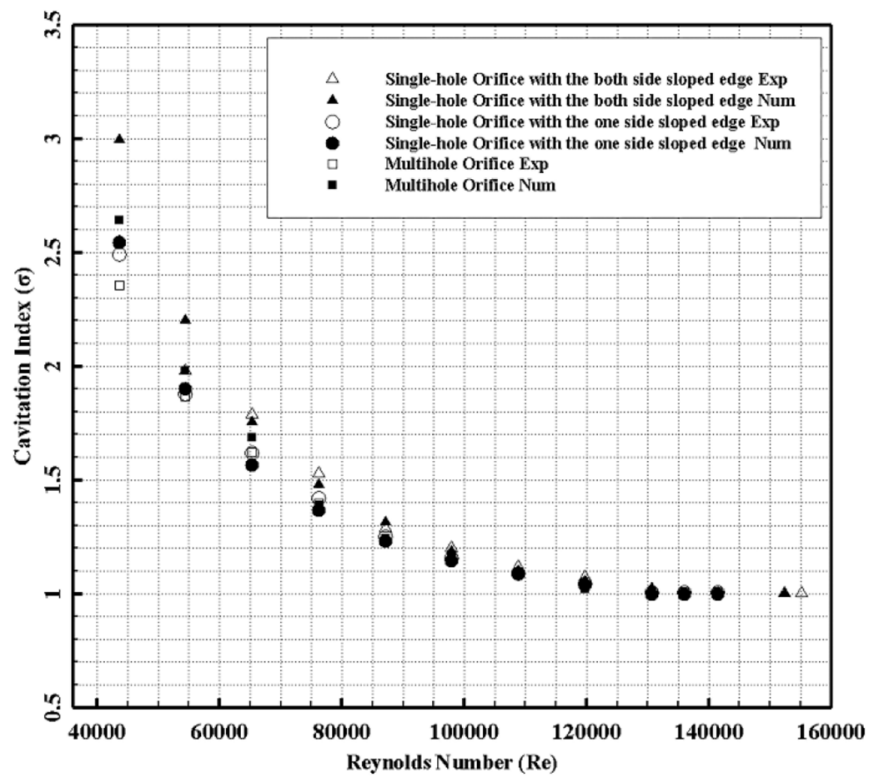

Fig. 19. Comparison of the resulted cavitation index trends as a function of the Re in the numerical and experimental analysis for orifices with the same EDR of 0.4 including: 1- a single--hole orifice with a two-sided sloped edge, 2 - a single-hole orifice with a one-sided sloped edge, and 3 - a multi-hole orifice.

lower Re was lower than that obtained from the experiments. By elevating the Re, not only the difference between the numerical and experimental results decreased, but also the contrasts between all the obtained results were greatly reduced. In order to analyze the changes of the cavity length created in the numerical models, the phase contour obtained from the simulation of the single-hole doubleslopededge orifice with a compression ratio of 0.4 is represented in Figure 20.
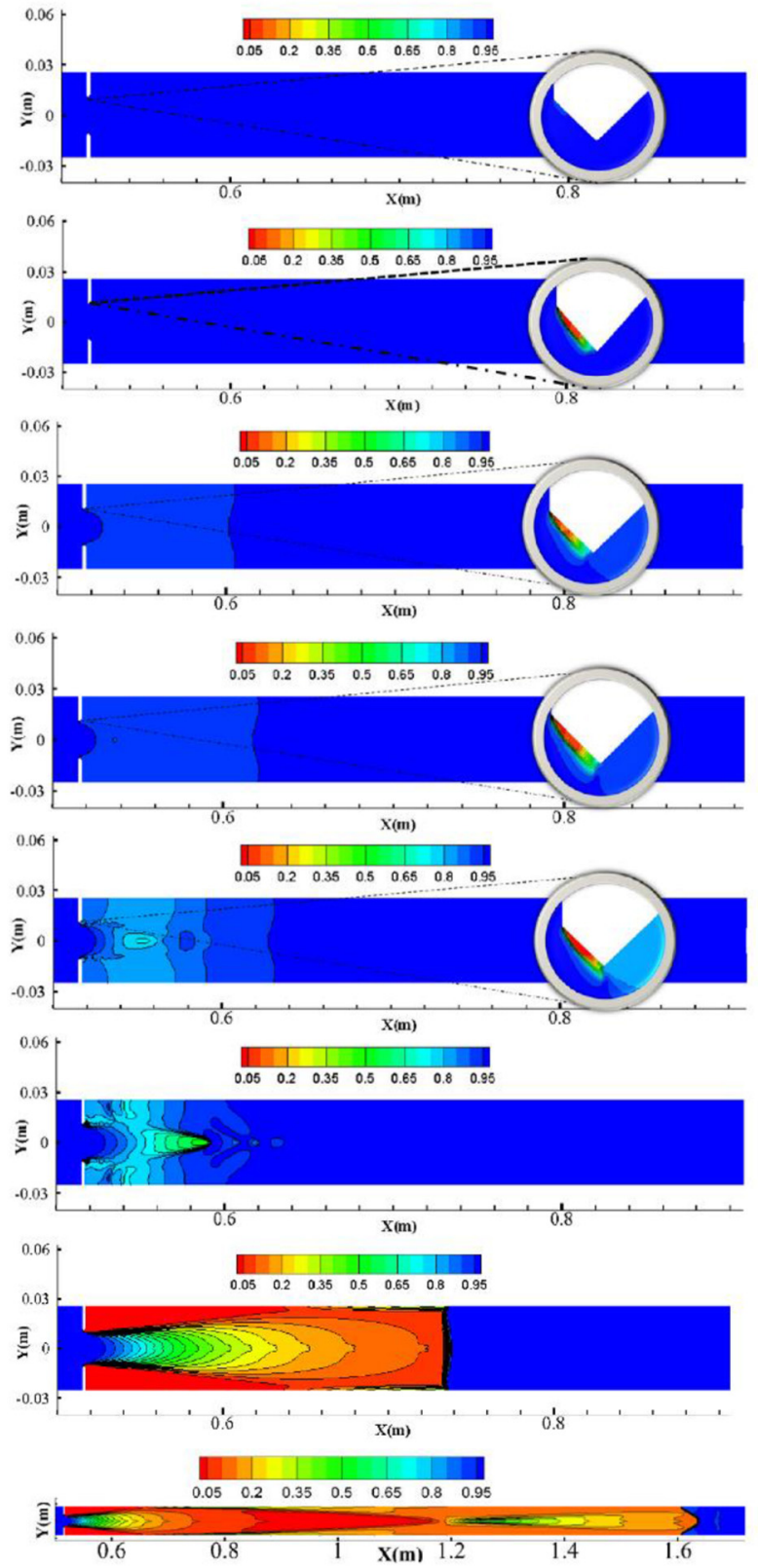

Fig. 20. The contour of cavitation volume in the orifice with $\beta=0.4$ in the flow of (a) 14 (b) 16 (c) 18 (d) 20 (e) 22 (f) 24 (g) 26 (h) $28 \mathrm{~m}^{3} / \mathrm{h}$.

As it is observed for the lower and initial flow rates, the simulated cavitation had lower accuracy for the cavity length. This holds up to the flow rate of 24 . The downstream flow at lower Reynolds experienced a lower pressure drop than the pressure difference between the upstream flow and the vapor pressure. In other words, the mean static pressure of the downstream flow is higher than the vapor pressure at the ambient temperature. Therefore, the cavitation in these flow regimes is due to the local pressure loss in some points which is caused by the turbulent eddies and vortex. In this kind of flow, incipient cavitation occurs, in which the difference between the experiential and numerical results is higher. It continues up 

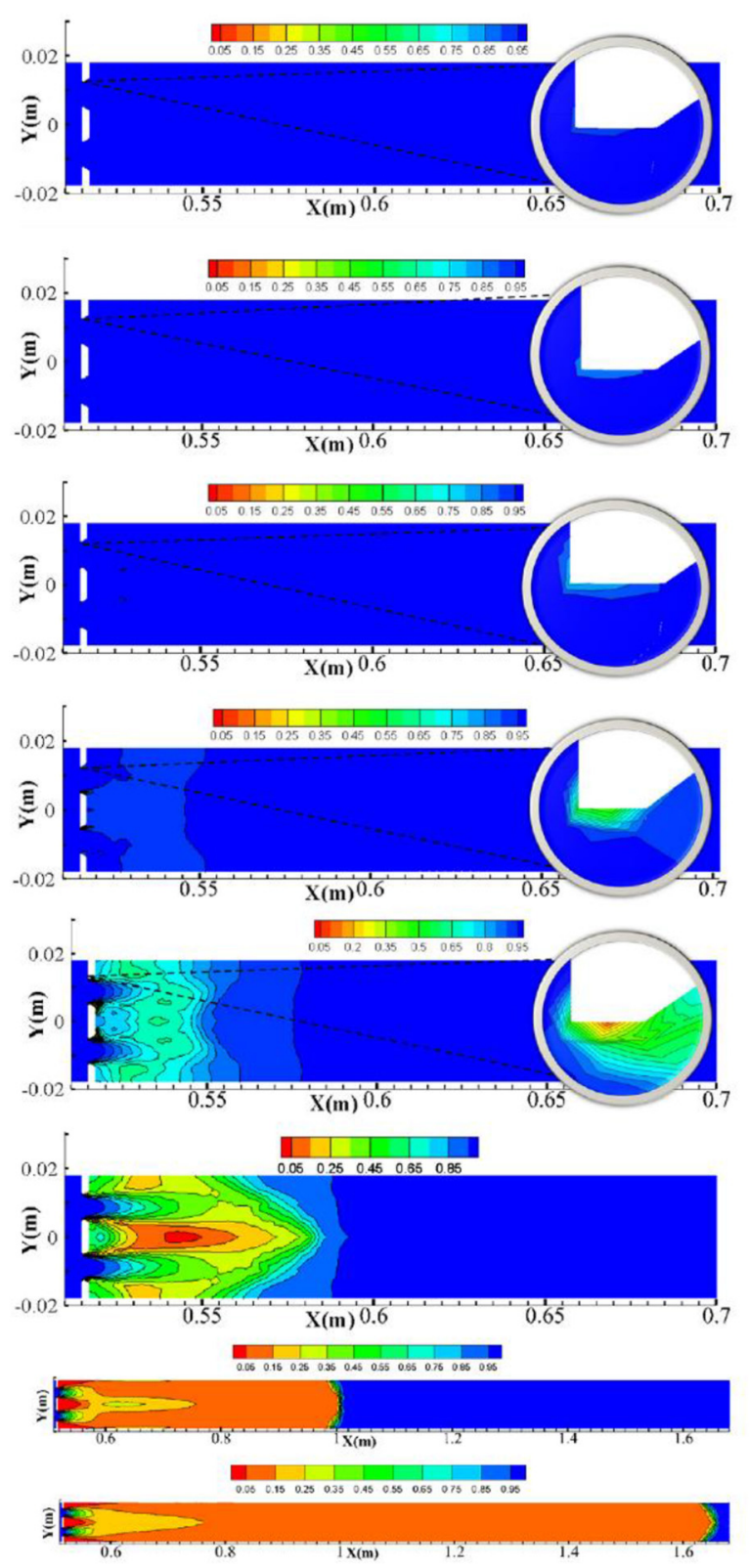

Fig. 21. The contour of cavitation volume in multi-hole orifice with $\mathrm{EDR}=0.4$ and in the flow of (a) 14 (b) 16 (c) 18 (d) 20 (e) 22 (f) $24(\mathrm{~g}) 25(\mathrm{~h}) 26 \mathrm{~m}^{3} / \mathrm{h}$.

to the flow rate of $24 \mathrm{~m}^{3} / \mathrm{h}$, at which flow enters the higher cavitation zone. The error between experimental and numerical results can be reduced by using unsteady simulations.

Moreover, in the simulation of the second section experiments of this study, which included modeling of water flow through orifices with the same EDR of 0.4 , the single-hole orifice with a one-sided sloped edge and the multi-hole orifice were simulated in three dimensions. From the conducted numerical investigations, the contour of mass fraction of water is displayed in Figure 21. As shown in the presented contours, cavitation increased clearly with the growth of the flow rate. In the early stages of cavitation in the incipient cavitation range, a great difference was observed between the results obtained from

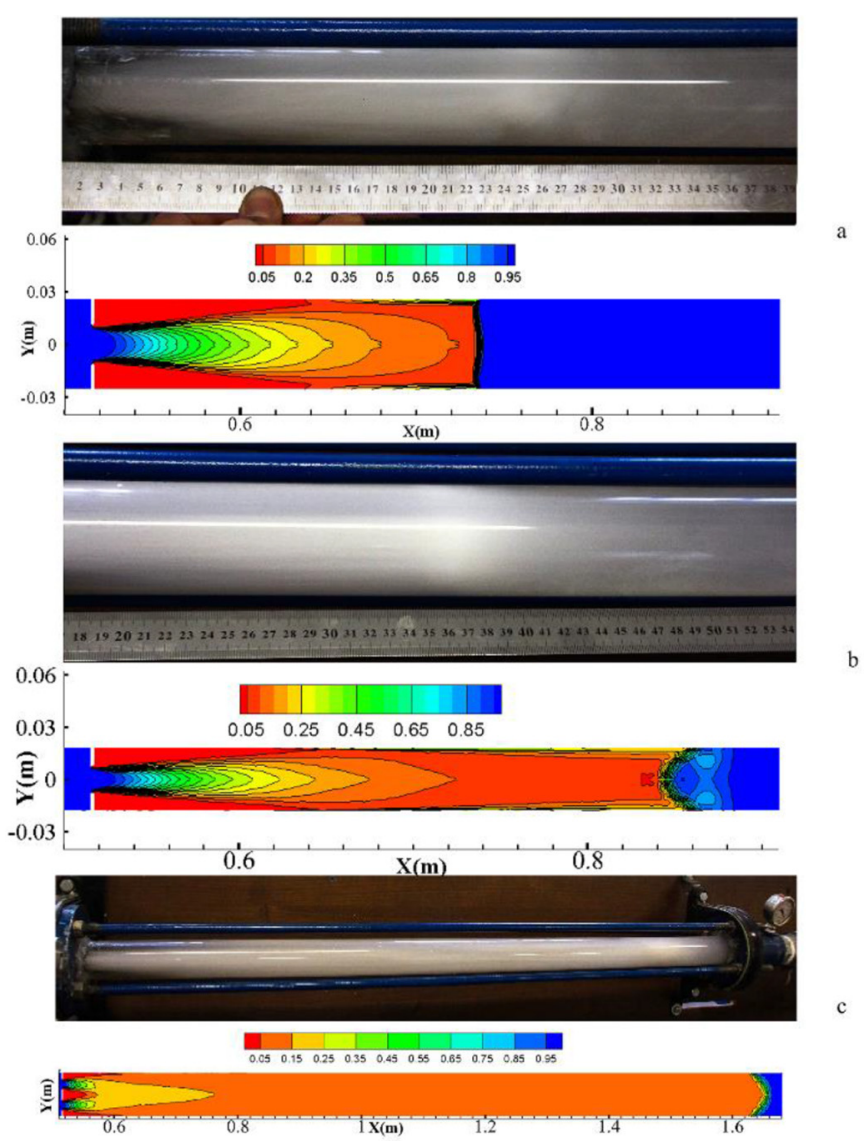

Fig. 22. The comparison of cavitation length in the flow of $26 \mathrm{~m}^{3} / \mathrm{h}$ resulted by the experimental and numerical tests in: (a) a single-hole orifice with a two-sided sloped edge (b) a single-hole orifice with a one-sided sloped edge and (c) a multi-hole orifice.

the experimental and numerical experiments. However, with increasing cavitation at 25 and $26 \mathrm{~m}^{3} / \mathrm{h}$ in the greater cavitation flow regime, the numerical and experimental lengths of cavitation were less different. Furthermore, by comparing cavitation length in the same flow rate through orifices with the same EDR, it was concluded that the amount of cavitation occurring in each flow rate was undoubtedly lower through the single-hole orifice with a two-sided sloped edge compared to the other similar orifices. Eventually, it can be observed that flow into the orifice with a two-sided sloped edge had a higher discharge coefficient. Therefore, in a given discharge through the same orifices, the one with a two-sided sloped edge led to the minimum length of cavity due to the least pressure drop across the plate.

In Figure 22, a comparison was carried out regarding the generated cavitation length in the numerical and experimental tests in a discharge of $26 \mathrm{~m}^{3} / \mathrm{h}$ through the mentioned orifices. The orifice plates in thesimulated models were located at $0.515-0.517 \mathrm{~m}$ in the horizontal axis; thus, the simulated cavity lengths were $22.5,36.5$, and $116 \mathrm{~cm}$, respectively, through a single-hole orifice with a two-sided sloped edge, a single-hole orifice with a one-sided sloped edge and a multi-hole orifice. These results according to the experimental results revealed that the 
orifice with a two-sided sloped edge caused the least cavitation length at a same discharge.

\section{Conclusions}

In this paper, the characteristics of the cavitation flow through the horizontal pipe and orifices at the contraction ratio (diameter ratio) of $0.3,0.4,0.5$ and 0.6 with a twosided sloped edge were numerically and experimentally compared and the results of the generated noise, cavitation length and cavitation number were presented. In addition, the effect of the orifice edge geometry was investigated in the orifices with similar equal diameter ratio (EDR) of 0.4 . It was determined that the single-hole orifice with a sloped edge of both the inlet and outlet sides caused the minimum pressure drop. The passing flow through this orifice had a higher cavitation number and a lower discharge coefficient compared to the orifices with only one-side (outlet side) sloped edge in the same flow rate. The length of the cavity was numerically and experimentally analyzed, and it was found that, in general, the orifices with a two-sided sloped edge in the same discharge caused a shorter cavity length. However, the comparison between the results of orifices with a one-sided sloped edge (including a single-hole and a multi-hole) was divided into two parts. At the same flow rates lower than $22 \mathrm{~m}^{3} / \mathrm{h}$, the multi-hole orifice produced lower cavitation, while at the flow rates greater than $22 \mathrm{~m}^{3} / \mathrm{h}$, it is exactly the opposite. Moreover, in the same pressure difference and in pressure less than 4 bar across the orifice plate, the length of the cavity caused by the singlehole orifices with the same diameter ratio was approximately equal and more than the cavity length caused by the multi-hole orifice plate. However, with increasing pressure difference to more than 4 bar, the single-hole orifice with a one-sided sloped edge caused the least cavity length. Incipient cavitation was also studied. It was concluded that among the mentioned orifices, the incipient cavitation of the multi-hole orifice was higher.

In order to convergence the calculation of the Singhal cavitation model along with the SST k-w turbulence solution method, it is necessary to initiate the calculation with the single-phase flow without any phase change, then enhance the calculation to multi-phase after the convergence in single-phase. Moreover, it is essential to lower the relaxation factors depending on the Ansys instruction to avoid divergence. Convergence in the computing of the present case is extremely complex to reach and timeconsuming, thus using a 2-D simulation as far as possible is much more efficient than 3-D modeling.

This work was supported by the Research Program of the Department of Mechanical Engineering, Shahid Rajaee Teacher Training University, Tehran, Iran.

\section{References}

[1] K. Manmatha, K. Sukanta, Single phase and two-phase flow through thin and thick orifices in horizontal pipes, Journal of Fluids Engineering 134, 091301-1-14 (2012)
[2] J. Wu, A. Wan, Flows through energy dissipaters with sudden reduction and sudden enlargment forms, Journal of Hydrodynamics 22, 360-365 (2010)

[3] M.G. De Giorgi, D. Fontanarosa, A. Ficarella, Characterization of cavitating flow regimes in an internal sharp-edged orifice by means of Proper Orthogonal Decomposition, Journal of Experimental Thermal and Fluid Science 9 , 242-256 (2018)

[4] P. Testud, P. Moussou, A. Hirschberg, Y. Aurégan, Noise generated by cavitating single-hole and multi-hole orifices in a water pipe, Journal of Fluids and Structures 23, 163-189 (2007)

[5] Z. Zhang, J. Cai, Compromise orifice geometery to minimize pressure drop, Journal of Hydraulic Engineering 125, 1150-1153 (1999)

[6] M. Reader-Harris, N. Barton, D. Hodges, The effect of contaminated orifice plates on the discharge coefficient, Journal of Flow Measurement and Instrumentation 25, 2-7 (2012)

[7] K. Ramamurthi, S.R. Patnaik, Influence of periodic disturbances on inception of cavitation in sharp-edged orifices, Journal of Experiments in Fluids 33, 720-727 (2002)

[8] K. Kowalski, S. Pollak, R. Skoda, J. Hussong, Experimental study on cavitation induced air release in orifice flows, Journal of Fluids Engineering, 140, 061201-1-7 (2017)

[9] W. Ai, T. Ding, Orifice plate cavitation mechanism and its influencing factors, Water Science and Engineering 3, 321-330 (2010)

[10] W. Ai, J. Wang, Minimum wall pressure coefficient of orifice plate energy dissipater, Water Science and Engineering 8, 85-88 (2015)

[11] T. Ding, Y. Wang, Comparison research on hydraulic characteristics of three type's orifice plate, The Open Fuels \& Energy Science 8, 43-46 (2015)

[12] W. Jianhua, A. Wanzheng, Z. Qi, Head loss coefficient of orifice plate energy dissipato. Journal of Hydraulic Research 48, 526-530 (2010)

[13] T. Zhao, J. Zhang, L. Ma, A general structural design methodology for multi-hole orifices and its experimental application, Journal of Mechanical Science and Technology 25, 2237-2246 (2011)

[14] J.P. Tullis, Hydraulics of pipelines. Pumps, valves, cavitation, transients, John Wiley \& Sons, New York, 1989

[15] D. Maynes, G.J. Holt, J. Blotter, Cavitation inception and head loss due to liquid flow through perforated plates of varying thicknes, Journal of Fluids Engineering 135, 031302-1-11 (2013)

[16] G. Ferrarese, G.V. Messa, M. Rossi, S. Malavasi, New method for predicting the incipient cavitation index by means of single-phase computational fluid dynamics model, Journal of Advances in Mechanical Engineering 7, 1-11 (2015)

[17] J.P. Tullis, Cavitation Guide for Control Valve. NRC Publication NUREG/CR-6031, U.S. Nuclear Regulatory Commission, Washington, D.C. (1993)

[18] Considerations for evaluating control valve cavitation. Report no. ISA-RP75.23-1995, Durham, NC: Research Triangle Park, (1995). http://webdelprofesor.ula.ve/ingen ieria/oscaror /CursosDictados / web \% 20instrumentaion \% 20industrial $/ 3 \% 20$ desarrollo\%20de $\% 20$ proyectos $/$ normas $\%$ 20ISA/STANDARD/RP_7523.PDF 
[19] Industrial-process control valves (CEI IEC 60534-8-2), 2nd ed., Bureau central de la Commission Electrotechnique Internationale, Geneva, 2005

[20] M.R. Chowdhury, Determination of pressure loss and discharge coefficients for non-Newtonian fluids in long square edged orifices, Master of Technology Dissertation, Department of Chemical Engineering, Cape Peninsula University of Technology, 2010

[21] N. He, Z. Zao, Theoretical and numerical study of hydraulic characteristics of orifice energy dissipator, Water Science and Engineering 3, 190-199 (2008)

[22] W. Zheng, Z. Qi, Hydraulic characteristics of multi-stage orifice plate, Journal of Shanghai Jiaotong University 19, 361-366 (2014)

[23] P. Testud, Noise generated by cavitating single-hole and multi-hole orifices in a water pipe. Journal of Fluids and Structures 23, 163-189 (2007)

[24] M. Fossa, G. Guglielmini, Pressure drop and void fraction profiles during horizontal flow through thin and thick orifices, Experimental Thermal and Fluid Science 26, 513-523 (2002)

[25] Y. Yan, R.B. Thorpe, Flow regime transitions due to cavitation in the flow through an orifice, International Journal of Multiphase Flow 16, 1023-1045 (1990)

[26] Z. Zhang, J. Cai, Compromise orifice geometry to minimize pressure drop, Journal of Hydraulic Engineering 125, 11501153 (1999)

[27] J. Wu, A. Wanzheng, Head loss coefficient of orifice plate energy dissipator, Journal of Hydraulic Research 48, $526-530(2010)$

[28] K. Takahashi, H. Matsua, Cavitation charactericstics of restriction orifices, Proceedings of 4 th International Symposium on Cavitation, CAV2001: sessionA9.006 (2001)

[29] W. Ai, Energy dissipation characteristics of sharp-edged orifice plate, Advances in Mechanical Engineering 7, 1-6 (2015)

[30] P. Rudolf, D. Kubina, J. Kozák, M. Hudec, F. Pochylý, Dynamics of the cavitating flow downstream of the orifice plate, AIP Conference Proceedings 1889, 020033 (2017)

[31] A. Simpson, V. Ranade, Modelling of hydrodynamic cavitation with orifice: influence of different orifice designs,
Journal of Chemical Engineering Research and Design 136 698-711 (2018)

[32] C.R. Mali, A.W. Patwardhan, G.K. Pandey, I. Banerjee, V. Vinod, CFD study on the effect of various geometrical parameters of honeycomb type orifices on pressure drop and cavitation characteristics, Journal of Nuclear Engineering and Design 370, 110880 (2020)

[33] ISO 5167, Measurement of fluid flow by means of pressure differential devices inserted in circular cross-section conduits running full Part 1: General principles and requirements, 2003

[34] G.G. Dastane, H. Thakkar, R. Shah, S. Perala, J. Raut, A.B. Pandit, Single and multiphase CFD simulations for designing cavitating venturi, Journal of Chemical Engineering Research and Design 149, 1-12 (2019)

[35] J. Bardina, P. Huang, T. Coakley, J. Bardina, P. Huang, T. Coakley, Turbulence modeling validation, in: 28th Fluid Dynamics Conference, California (1997)

[36] F. Menter, Zonal two equation $\mathrm{k}-\mathrm{w}$ turbulence models for aerodynamic flows, 23rd Fluid Dynamics, Plasma dynamics and Lasers Conference, American Institute of Aeronautics and Astronautics, 1993

[37] A. Simpson, V.V., Ranade, Modelling of Hydrodynamic Cavitation with Orifice: Influence of different orifice designs. Chem. Eng. Res. Des. 136, 698-711 (2018)

[38] G.H. Schnerr, J. Sauer, Physical and numerical modeling of unsteady cavitation dynamics, Fourth International Conference on Multiphase Flow, 2001

[39] P.J. Zwart, A.G. Gerber, T. Belamri, A two-phase flow model for predicting cavitation dynamics, Fifth International Conference on Multiphase Flow, Japan, 2004

[40] A.K. Singhal, M.M. Athavale, H. Li, Y. Jiang, Mathematical basis and validation of the full cavitation model, Journal of Fluids Engineering 124, 617-624 (2002)

[41] B. Ebrahimi, G. He, Y. Tang, M. Franchek, D. Liu, J. Pickett, F. Springett, D. Franklin, Characterization of high-pressure cavitating flow through a thick orifice plate in a pipe of constant cross section, International Journal of Thermal Science 114, 229-240 (2017)

Cite this article as: M.R. Davoudi, M. Mahdi, Experimental and numerical investigation of geometric effect on cavitation flow through orifice, Mechanics \& Industry 22, 31 (2021) 